Portland State University

PDXScholar

$5-17-1983$

\title{
Career Supports and Career Mentors: an Analysis of Their Prevalence and Their Relation to Career Success and Satisfaction Among a Group of Women Lawyers
}

Sandra Lee Riley

Portland State University

Follow this and additional works at: https://pdxscholar.library.pdx.edu/open_access_etds

Part of the Industrial and Organizational Psychology Commons, and the Work, Economy and Organizations Commons Let us know how access to this document benefits you.

\section{Recommended Citation}

Riley, Sandra Lee, "Career Supports and Career Mentors: an Analysis of Their Prevalence and Their Relation to Career Success and Satisfaction Among a Group of Women Lawyers" (1983). Dissertations and Theses. Paper 3344.

https://doi.org/10.15760/etd.5002

This Thesis is brought to you for free and open access. It has been accepted for inclusion in Dissertations and Theses by an authorized administrator of PDXScholar. Please contact us if we can make this document more accessible: pdxscholar@pdx.edu. 
AN ABSTRACT OF THE THESIS OF Sandra Lee Riley for the Master of Science in Psychology presented May 17, 1983.

Title: Career Supports and Career Mentors: An Analysis of Their Prevalence and Their Relation to Career success and Satisfaction Among a Group of Women Lawyers.

APPROVED BY MEMBERS OF THE THESIS COMMITTEE:

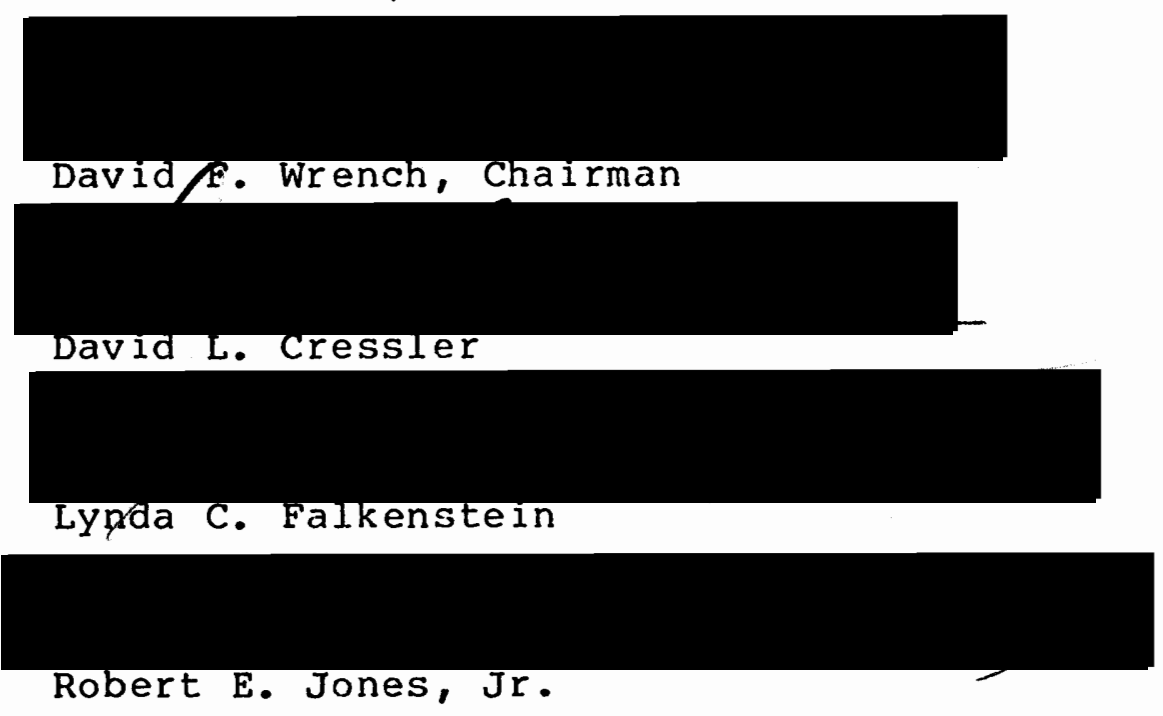

This study investigated three issues problematic to the state of knowledge on mentoring. These issues were: (a) lack of scientifically derived operational definitions in use in research on mentoring; (b) lack of agreement about how common mentoring is; and (c) lack of agreement about whether or not alternate forms of career support are more efficient than mentoring. The information collected to address each of these issues was acquired in two phases: a literature survey 
followed by a sample survey. The literature survey addressed the first issue. It resulted in the formulation of an operational definition of mentoring which was based on an empirical profile of an "ideal" mentoring relationship. Formulation of the profile was a major focus of this study.

The operational definition derived was presented as a questionnaire item in the second phase of this study, i.e., the sample survey. Data gathered from the questionnaire, which was mailed to 361 women lawyers, were used to address the issues of the commonness of mentoring and the efficacy of mentoring. Responses to the questionnaire numbered 185 (55\% response rate).

Thirty-five percent of the women in this study had experienced a mentoring relationship, as defined in this study. This result was discussed as being an outcome of the systematic methodology used in this study to assess the prevalence of mentoring. Further, this study presented support for the view that variable methods of operationalizing mentoring result in variable findings on its prevalence.

With regards to the efficacy of mentoring versus other forms of career support, the following were found: First, 28 percent of the respondents were identified as being in receipt, from more than one person, those forms of support which mentored women receive from a single person. These women were termed "pseudo-mentored". The remaining 37 
percent of the respondents were termed "not significantly career supported". Second, neither of the two latter forms of support were significantly positively correlated with career satisfaction and success (as measured by six likerttype items) while being mentored was. Further, because of statistical differences in mean ratings on outcome variables, mentoring appeared as a significantly more efficient form of career support than both "pseudo-mentoring" and being "not significantly career supported". Importantly, those women who were "pseudo-mentored" were more likely to report themselves as satisfied and successful than those "not significantly career supported", but not statistically significantly so. 
CAREER SUPPORTS AND CAREER MENTORS: AN ANALYSIS

OF THEIR PREVALENCE AND THEIR RELATION TO

CAREER SUCCESS AND SATISFACTION AMONG

A GROUP OF WOMEN LAWYERS

by

SANDRA LEE RILEY

A thesis submitted in partial fulfillment of the requirements for the degree of

MASTER OF SCIENCE

in

PSYCHOLOGY

Portland State University

1983 
TO THE OFFICE OF GRADUATE STUDIES AND RESEARCH:

The members of the Committee approve the thesis of Sandra Lee Riley presented May 17, 1983.

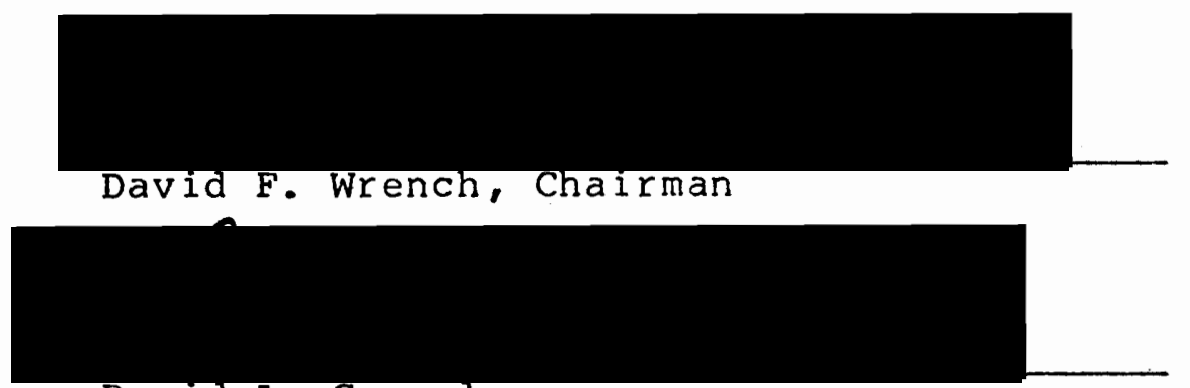

David L. Cressler

Lynda c. Falkenstein

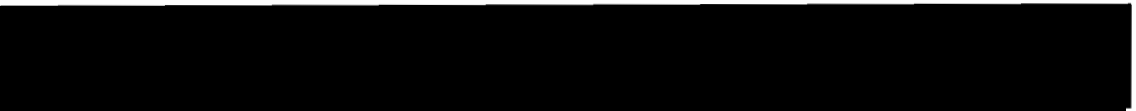

Robert E. Jones, Jr.

\section{APPROVED :}

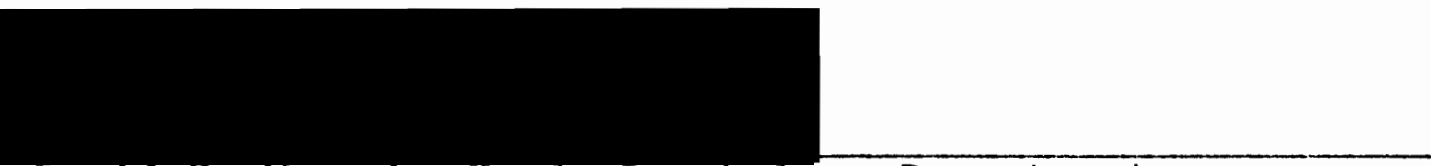

David F. Wrench, Head, Psychology Department

Stanley E.'Rauch, Dean of Graduate Studies and Research 
TABLE OF CONTENTS

PAGE

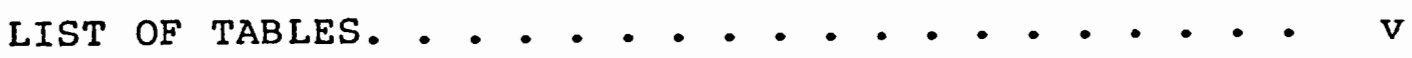

LIST OF FIGURES . . . . . . . . . . . . . . vii

CHAPTER

I INTRODUCTION TO CONCEPT OF MENTORING • • 1

Influence on Personal Development . . . 3

Influence on Career . . . . . . . 5

it PRESENTATION OF THE PROBLEM . . . . . 8

Definition Problem. . . . . . . 8

How Common is Mentoring?. . . . . . 10

How Desirable is Mentoring? . . . . 13

III THESIS GOALS. . . . . . . . . 16

Goal 1. . . . . . . . . . 17

Goal 2. . . . . . . . . . 17

Goal 3. . . . . . . . . . 18

IV DEFINING AND OPERATIONALIZING

MENTORING • . . . . . • • . • . 20

Method Used to Operationalize

Mentoring . . . . . . . . . 20

Reports surveyed. . . . . . . . 22

Functions and Characteristics of the

Mentoring Relationship Listed . . . . 25 
Assessing the Prevalence of Mentoring:

The Career Support Scale. . . . . . 34

V SAMPLE SURVEY . . . . . . . . 38

procedures. . . . . . . . . 38

Subject Response. . . . . . . . 40

Analysis of Data. . . . . . . . . 41

Representativeness of Sample. . . . . 42

Demographic Characteristics of Survey

Respondents... . . . . . . . . 44

VI PREVALENCE OF MENTORING AND OTHER

FORMS OF CAREER SUPPORT . • • . . . . . 49

Assessing Type of Career Support With

Career Support Scale. . . . . . . 49

Prevalence of Mentoring . . . . . . 51

Identifying Career Supports other

Than Mentors. . . . . . . . . . 59

VII RELATIONSHIPS BETWEEN CAREER SUPPORT

TYPE AND CAREER SUCCESS AND

SATISFACTION. • • • • . • • . • 63

VIII SUMMARY, CONCLUSIONS, AND

RECOMMENDATIONS •. . . . . . . . . 74

REFERENCES. • • • • • • • • • • • • • • 81

APPENDICES. . . . . . . . . . . . 86

A. Survey Instrument

B. Cover Letter, Follow-up Cover

Letter, Text of Phone Message,

Reminder Postcard

C. Informed Consent

D. Representativeness of Sample Data

E. Career Supports by Role

F. Data on a Typical Pseudo-Mentored Subject

G. Tables 
LIST OF TABLES

TAB LE

PAGE

I Survey Response. . . . . . . . . . •

II Distribution of Ages . . . . . . . .

III Year of Law School Graduation. . . . . .

IV Current Work Position. . . . . . . .

$\mathrm{V}$ Income . . . . . . . . . . . . .

VI Mean Relationship Between Scales......

VII Distribution of Mentors. . . . . . . .

VIII Prevalence of Mentoring as Measured

by Subject Response to a

"Traditional" Question. . . . . . .

IX Mean Scores and Standard Deviations of

Eight Career Satisfaction and

Success Measures. - . - . - . • •

$\mathrm{X}$ Correlations Between Career Satis-

faction and Success Measures. . . .

XI Zero-order and Some First-order

Correlations on Variables of

Interest with Career Satis-

faction Measures. . . . . . . .

XII Zero-order and Some First-order Corre-

lations on Variables of Interest

with Career Success Measures . . . 
XIII Distribution of Ages for INITIAL and

LATER Groups. . . . . . . . . 102

XIV Year of Law School Graduation for the

Groups of INITIAL and LATER . . . . 103

XV Income for Groups of INITIAL and LATER . . 104

XVI Results of Tests of Statistical

Difference for Groups of INITIAL

and LATER on Demographic Variables. . 104

XVII Career Supports by Role. . . . . . . 107

XVIII Data on a Typical Pseudo-Mentored

Subject . . . . . . . . . 109

XIX Intercorrelations of All Variables of

Interest to This Study. . . . . . 111

XX Summary Results of Two-Tailed T-Tests

on Satisfaction Measures Based on

Type of Career Support. . . . . . 112

XXI Summary Results of Two-Tailed T-Tests

on Success Measures Based on

Type of Career Support. . . . . . 114 


\section{LIST OE EIGURES}

FIGURE

PAGE

1. Papers Used to Identify Functions and

Characteristics of Mentoring

Relationship. • . . . . . . • • • .

2. Defining Mentoring in Terms of the

Character of the Relationship and

the Functions it Serves . . . . . . . 28 


\section{CHAPTER I}

\section{INTRODUCTION TO CONCEPT OF MENTORING}

Greater and greater numbers of women are entering traditionally male-dominated fields. The success they ultimately achieve in these fields will be dependent upon a large number of variables. One of the variables that has emerged as particularly significant is the informal support one receives in the course of developing her career. Informal' support is in contrast to formal support--institutions or individuals organized specifically for the purpose of providing support services. In the area of career development, examples of formal support would be vocational schools, career counselors/advisors, and personnel managers. Informal support, on the other hand, is not formally organized; but has the potential to be equally influential. Sources of informal support that have been found to influence career development as well as adult development in general are parents, other relatives, peers, teachers, employers, spouses and other individuals (Almquist, 1971; Bell, 1970; Goldstein, 1979; Hoffman, 1972; Super, 1957, 1969; Vanzant, 1981; and others).

Many theorists have written about the importance to one's career of the informal social network that pervades 
most work settings (e.g., Epstein, 1970; Jennings, 1971; Kanter, 1978). It is generally agreed that one's success within a profession stems largely from the help and support received from others in the work setting or within the profession. Cook (1979) writes:

It's widely accepted management theory today that a person cannot make it alone inside the corporation, no matter how good the technical skills, abilities, performance or stamina. The quality of work is important, but the willingness of people on the key executive team to support an aspiring manager, counsel with the person and provide inside information is the key to an individual's success.

According to a growing body of literature the ideal form of informal support is mentoring. Mentoring exists when a more experienced professional person (mentor) takes a special interest in helping a younger person (mentee) advance in his or her profession. A mentor helps by acquainting the young person with values, customs, resources, and persons within the system, by teaching skills and warning of pitfalls. A mentor watches out for the mentee's interests and helps him or her move ahead, offering support and encouragement along the way. A.mentor is felt to play an important role in helping the mentee define and/or reach his or her life goals.

The above description might be said to represent the "classic" or "traditional" model of a mentor. In a classic or traditional mentoring relationship the mentor performs more than one function, for example, he or she teaches, counsels and provides emotional support. It is important 
to remember that in a classic or traditional mentoring relationship the mentor performs all these functions and more, but never less. Thus, a mentor can be distinguished from an individual who is supportive of one's career and who may perform single functions on the person's behalf. Some writers include in the term mentor anyone who plays any sort of influential role in one's career. It is debatable whether this practice should continue or whether the term mentor should be reserved for a person more closely resembling the classic model described above. The dangers of using the term loosely and without precision are discussed below.

Influence on Personal Development

Numerous individuals have written of the effect on one's life of having a mentor. One such individual is Daniel Levinson (1978). Levinson's ideas are based on intensive interviews of 40 men (no women) from four diverse occupational areas. The interviews provided the material for his book, The Seasons of a Man's Life, in which he described adult developmental stages through which men pass. Within the book he described in detail "the complex and developmentally important" mentoring relationship. Levinson wrote that forming a relationship with a mentor is a major developmental task of early adulthood. He described the mentor as a mixture of parent and peer and as 
one who is perceived by the mentee as a responsible, admirable, older sibling. The primary function of the mentor, Levinson said, is to act as a transitional figure, helping the young person in his transition from early to middle adulthood. Levinson wrote:

In the usual course, a young man initially experiences himself as a novice or apprentice to a more advanced, expert, and authoritative adult (the mentor). As the relationship evolves he gains a fuller sense of his own authority and his own capability for autonomous responsible action. The balance of giving and receiving becomes more equal. The young man increasingly has the experience of 'I am' (an adult) and the relationship becomes more mutual. This shift serves a crucial developmental function for the young man: he transcends the father-son, man-boy division of his childhood (p. 99).

A further influence on the mentee's development was suggested by Levinson. He wrote: "The mentee takes admired qualities of mentor more fully into himself. He may become better able to learn from himself, to listen to voices within himself. The internalization of significant figures is a major source of development in adulthood" (p. 100).

Kellerman (1978) has also described, via a case study of the politican, Willy Brandt, and his mentors, the qualitative impact a mentor can have on the mentee's transition from early to middle adulthood, as well as on adult life itself. The author has described the origins, nature and termination of the Brandt-Julius Leber relationship. It was pointed out that the influence of the mentor on the mentee transcended the period of their actual interaction. 


\section{Influence on Career}

That mentoring can influence one's career has been reported in a number of studies. For example, Roche (1979) reported in his survey of over 1,200 of the nation's top business executives (of which women comprised less than one percent of the sample) that those individuals who had experienced a mentoring relationship were generally happier in their jobs than their colleagues who had no mentor. They also tended to enter higher earning brackets at an earlier age. Fitt and Newton (1981) found that their respondents --female managers holding jobs relatively similar to one another--who reported a relationship with a mentor were, on the average, better paid and younger than those reporting no mentor as a part of their career background.

Mentors were seen to have positively affected career development for a group of female college administrators in a 1981 study by Bova and Phillips. One protege in the study reported: "I just can't get over how it... changed the direction of where I was going." In her popular book, Passages, Gail Sheeny notes "almost without exception the women studied who did gain recognition in their careers were at some point nurtured by a mentor."

Hennig and Jardim's (1977) detailed account of 25 women working at the highest executive levels in major corporations includes descriptions of the close relation- 
ships that developed between each woman and her male boss. The encouragement and support of the male boss was a critical factor in each woman's success. "To each woman, he was her supporter, her encourager, her teacher and her strength in the company," Hennig and Jardim wrote. Each felt her boss believed in her competence and her will to succeed. Generally, he was her protector and advocate for a full decade as her career progressed.

studies such as those reported in this section and the one before it have appeared in the popular media as well as in professional journals. Collectively, the findings have indicated that everyone ought to have a mentor in order to insure success and satisfaction in her chosen career. Indeed much of the literature aimed at advising women on how to succeed in traditionally male jobs has been written to include instructions to the effect "go find yourself a mentor" (e.g., Burkhardt, 1979; Halcomb, 1980; Loring, 1979; Kanter, 1977; Marsicano, 1981; Merken, 1977; Thompson, 1976). Many of these sources have given information on how to find a mentor (e.g., George \& Kummerow, 1981; Schmidt \& Wolfe, 1980; Thompson, 1976), what to look for in a potential mentor (e.g., Halatin, 1981; Marsicano, 1981), and what one might consider about involvement in such a relationship (LaFrance, 1981, 1982).

Is all this advice premature? Are mentors truly critical to professional advancement? Questions such as 
these are beginning to surface in the literature. Such questions have surfaced because studies like those cited in the previous section have been legitimately faulted on methodological grounds. In addition, a number of individuals have recently suggested that forms of career support other than mentoring are not only more common but are more desirable (Burrow, 1980; Cook, 1979; Halcomb, 1980; Sheeny, 1976). The purpose of this thesis is to look at how a more systematic definition of mentoring may help to better understand the role of informal support in career development. 
CHAPTER II

PRESENTATION OF THE PROBLEM

Despite the popularity of mentoring as a concept there is no real agreement as to what it is, how common it is, or how desirable it is. Each of these issues is explored individually below.

\section{Definition problem}

From a scientific standpoint, there is no satisfactory definition of the word mentoring in existence (Speizer, 1981; Wrightsman, 1981). Wrightsman has argued that there is a "false consensus" about what the word mentoring means: that it is only at a "superficial level that everybody 'knows' what mentoring is." support is found for this argument by noting that researchers too often do not define for the reader their conception of mentoring in the paper reporting their findings (e.g., Burrow, 1980; Erickson \& Pitner, 1980; Fitt \& Newton, 1981; Kirchner, 1969; Stein, 1981a; Stein, 1981b). It appears that these researchers have assumed we know what they are referring to. Wrightsman has made an additional important observation. He has noted that "if a definition is given, it is offered without indication of the sources used for 
its formation." He has accused researchers of generating their own definitions "often without adequate contemplation." Indeed it appears that mentoring takes on different characteristics and definitions depending on who is describing mentoring. Wrightsman has warned us that it is not possible to develop mentoring as a scientific concept with "everyone doing his or her own theory." He has warned further that to continue to use the term loosely and without precision is to devalue it as a concept.

To support his arguments, Wrightsman has pointed to the operational definitions in use for research on this topic. In reality, the operational definitions vary widely among researchers. Thus, Wrightsman has argued, any conclusions drawn are limited to the particular definition used. This means that a number of conclusions about mentoring that have been made to appear self-evident are now drawn into question--not the least of which is that mentoring is a necessary prerequisite to career success and satisfaction.

Consequences of the Definition Problem. A review of the literature shows that one of the first issues addressed by researchers upon collection of their data is to determine how common mentoring is among their subjects. The traditional method for determining whether or not a subject has experienced a mentoring relationship has been to present some conceptualization of what a mentoring relation- 
ship is, and to ask the subject if she has ever experienced such a relationship. If the subject responds positively, this is interpreted to mean she has experienced a mentoring relationship.

Then only the data for those subjects who report having a mentor are used to investigate additional questions concerning the process of mentoring. Common questions about the process of mentoring include: Who is the mentor (male? female? What is the mentor's occupation? What is the mentor's status compared to his/her mentee?); What are some of the drawbacks and risks to the participants in the relationship? (e.g., sexual tension in crosssexed pairs); What are the dynamics of this complex interpersonal relationship?; Does the relationship evolve through stages?

Researchers have attempted to answer these questions with data collected by the traditional method. The answers, however, depend on who is included in the "mentored" group. Inconsistencies in defining mentoring has not only made the answers to these questions on process noncomparable from one study to the next. It also has made unanswerable the question of how common mentoring is in a population.

How Common is Mentoring?

A result of the lack of agreement on how to define mentoring has been a variety of findings about how common 
it is. In Roche's (1979) study, it was reported that twothirds of the 1,200 executives surveyed reported having a mentor. He based this on their response to the following question: "At any stage of your career, have you had a relationship with a person who took a personal interest in your career and who guided or sponsored you?" The following question was used by Missirian (1980) to operationalize mentor to her subjects: "Is there some one person (or perhaps more than one person) who stands out in your mind as the one who most influenced your career development at a critical junction? (Perhaps a boss, a senior staff person, a teacher, a consultant who helped you to acquire the professional skill and sophistication required to advance to higher corporate levels.)" A full 85 percent responded affirmatively. Cameron (1978) was interested in the degree of mentoring university faculty members received in their graduate school years. To ascertain this she operationalized "sponsorship" (defined by Cameron as "having a mentor") in terms of financial support, research and publication training, placement support, and personal/emotional support. In her study, Cameron viewed sponsorship as a part of her subject's support network and did not report a percentage of sponsored subjects. Kirchner's (1969) criteria for being a mentee was to respond in the affirmative to the following question: "We are interested in the influence of other people on the 
paths you have taken. If you can recall how some of the people have influenced you, please tell us what it was about the person or your relationship with him which made him influential." Seventy-six percent of her subjects reported an influence by another person.

The operational definition in Moore and SangariaDanowitz's (1979) study included the term mentor. Their question was phased as follows: "The term mentor refers to an individual who facilitiates career advancement by 'teaching the ropes,' coaching, serving as a role model, and making important introductions. Have you had a mentor during your career thus far?" Forty-seven percent of their subjects ( 83 female university administrators) answered "yes" to this question.

Phillips (1977) also chose to use the term mentor in the question posed her subjects. The question Phillip's subjects responded to was: "Some writers have described persons who have gone out of their way to help the careers of others. These are individuals other than family members who have taken persons 'under their wings' or 'groomed' them as they began and progressed in their careers. These helpers are sometimes called 'sponsors' or 'mentors'. As you reflect back on your career, please answer the following: My experience is that I had (a) one person whom I would call my mentor or sponsor; (b) no particular person 
could be called my mentor." Sixty-one percent affirmed they had a mentor.

Bova and Phillips (1981) spent nearly half a page defining mentoring to their subjects (160 men and women in varied professions) prior to asking them about their mentor experiences. After reading it they were asked, "do you feel that you have/had a mentor?" Ninety-two percent answered "yes". Shockley and staley (1980) simply asked their subjects ( 30 women in management training programs) "Do you have a mentor in the organization (where you work)?" They found 67 percent responding yes to this question.

The studies reviewed here demonstrate that quite variable rates of mentorship have been found. The percentage of subjects reporting having mentors ranged from 47 percent to 92 percent, with a median for the different studies of 66 percent. Since different definitions were used it is impossible to determine whether the different percentages found reflect actual differences in the populations being surveyed or whether they are artifacts of differences in methodology.

\section{How Desirable is Mentoring?}

Recent discussions in the literature have suggested that mentoring relationships are actually uncommon and that alternate forms of career support are more desirable. Such 
discussions involve the extent to which a traditional or classic mentoring relationship is experienced by today's woman professional. There is some feeling that rather than remaining "under the wing" of a single individual over the course of developing her career, a woman is experiencing instead, a series of "mentoring" relationships. In other words, women report having several different sources of support, each performing a different mentoring function. In light of earlier discussions about distinguishing mentors from those who perform individual support functions (p. 3), it is debatable whether theorists should continue to call these individuals mentors or whether there isn't a better term that would be more descriptive of the role they play in one's career.

Regardless of what term is used to refer to these individuals their appearance in place of traditional mentors has received increasing attention as witnessed by the following reports. One successful woman wrote in her review of the mentor experience:

"My personal learning experiences inside corporations make me feel that it is difficult and sometimes risky to find and become tied to a single mentor. A more successful approach for me has been one of enlisting the support of executives from each functional area and from several levels of the organization" (Cook, 1979).

Burrows (1980) has written that the women he studied indicated that "the concept of a single mentor is outdated and potentially dangerous as it may make the woman trainee even 
more vulnerable to an assumed failure." Sheeny (1976) has noted a trend away from mentoring relationships that last a lifetime. Rosabeth Moss Kanter said in her address to a national group of women deans, administrators, and counselors in 1979, "Very few people have classic mentors--one person through long periods of time" (in Burrows, 1980). Halcomb (1980) has noted that women seeking the right mentor often end up settling for several short term mentors, deriving some support from each one.

These writers then have suggested that it is rare and even undesirable to be mentored in the classic sense. They have indicated instead that access to a number of supportive individuals, each fulfilling important career related needs is an alternative to a classic mentor.

What role, then, can we expect mentoring to play in career development? It is clear from the above discussions that a scientific definition of mentoring is needed before this question and others (e.g., how common is mentoring?) can be answered. 
CHAPTER III

THESIS GOALS

Three issues problematic to the state of knowledge on mentoring were discussed in the previous chapter. First discussed was the issue of how mentoring should be defined. Evidence was presented which suggested that: (a) in order to scientifically develop mentoring as a concept, definitions should be based on the work of others, and (b) past definitions of mentoring were not based on that principle. Second, the issue of how common mentoring is was discussed. The argument was made that the variety of operational definitions used across studies plays a role in the variety of findings about how common mentoring is. The third issue discussed was the issue of whether or not alternate forms of career support are more desirable than mentoring. Presented were reports of individual beliefs that mentoring is actually rare and undesirable and that women should seek alternate forms of career support that meet the same needs as a mentoring relationship.

This study addressed each of these issues by, first, using systematically done studies to devise an operational definition of mentoring and, second, using this operationalization to collect data on the prevalence of mentoring, 
on the prevalence of alternate forms of career support and on the relationship of each to career outcomes. This was done by setting and then researching three goals. The first goal involved surveying the literature and the second and third goals involved surveying a sample of women professionals. Each goal is described below.

Goal 1

The concept of true mentoring was operationalized. This was accomplished through a literature review in which distinguishing features of the mentoring relationship were identified. As a part of this goal, the operationalization was used to design a measure (Career support scale or CSS) that could be used to assess the prevalence of mentoring among a group of subjects. An important aspect of this goal was the setting of criteria for distinguishing between those who had been mentored and those who had not.

Goal 2

The scale designed as a part of Goal 1 was administered to a group of women lawyers. The purpose was to collect data needed to answer the following questions: 
-How common is mentoring among the subjects of this study when the status of "being mentored" is dependent upon meeting a set of criteria set forth in this study?

-Can women be identified who do not have mentors (as defined by this study) but who are in receipt of the benefits of a mentoring relationship from a group of informal supports.

In addition the data were examined for the purpose of identifying two other groups of women: those who were in receipt of both forms of support (mentoring and a system of informal support) and those who lacked any significant career support.

Goal 3

In order to gain insight into the role mentoring and informal support systems may play in career development, relationships between type of career support and career success and satisfaction were investigated.

subjective measures of career success and satisfaction were coupled with the findings from Goal 2, to address the following questions:

-Is being mentored related to career success? career satisfaction?

-Is having a system of informal supports that provides the benefits on a mentoring relationship related to career success? career satisfaction? 
-Are other forms of support that might have been identified by this study related to career success? career satisfaction?

-Is one form of support more highly related to career success and satisfaction than the other forms of support identified in this study?

The results of the first goal are presented in Chapter

IV. The results of the second and third goals are reported in Chapters VI and VII, respectively. 


\section{CHAPTER IV}

\section{DEFINING AND OPERATIONALIZING MENTORING}

Traditional methods of operationally defining mentoring were criticized in the previous chapters on the grounds that they reflect the individual researcher's personal perceptions of the concept. Wrightsman (1981), in his critical review of methodologies in use for assessing mentoring, said that the danger of this procedure is that limited progress is made in developing the concept scientifically. He pointed out that "communication between researchers [is an] absolute necessity for the body of knowledge to grow" and that building on the work of others is the most effective route to a comprehensive theory of mentoring. The method used below to arrive at an operational definition of mentoring heeds this advice.

Method Used to Operationalize Mentoring

A statement by Daniel Levinson (1978) suggested a framework from which to begin to build an operational definition of mentoring. Levinson wrote, "Mentoring is not defined in terms of formal roles but in terms of the character of the relationship and the functions it serves" (p. 98). This indicated that mentoring could be opera- 
tionalized by identifying the combination of functions and characteristics which distinguish it as a unique form of informal support.

Clawson (1979) has written about mentoring in terms of the characteristics and functions of the relationship. In his theoretical analysis of the concept based on the literature that existed at that time he identified two significant aspects of the mentoring relationship. The first aspect is "comprehensiveness", meaning that a mentor is someone who plays more than one role or someone who performs more than one function. The second significant aspect is the characteristic of "mutuality," referring to the mutual respect, trust and affection experienced by the participants. Thus, Clawson's findings lend support to the notion that mentoring could be operationalized by identification of the functions and characteristics of the relationship.

This then is the approach that was used in this study to accomplish the goal of defining "true mentoring". The term true mentoring was adopted to refer to the relationship this study sought to define. The term, used hereafter, was intended to distinguish the relationship of interest to this study from other conceptions of mentoring, such as classic or traditional, which have not been scientifically defined. An exhaustive list of characteristics and functions of the true mentoring relationship was com- 
piled. In compiling this list, a number of selected studies were surveyed for what the author(s) concluded were functions and characteristics of the relationship. The list, which essentially represents all the functions and characteristics of an ideal mentoring relationship, served as the basis for forming an operational definition of true mentoring.

\section{Reports Surveyed}

In searching for an exhaustive list of functions and characteristics only certain reports were used. Those studies are listed in Figure 1. All available reports meeting one or more of the following criteria were included in the survey. First, that it was an original (versus second-hand) report of a study which intentionally collected data on the role mentors play in (or the impact they have on) one's life and/or career. A number of such studies have appeared in recent years. Those available and subsequently used were: Clawson (1979), Hennig and Jardim (1977), Klauss (1981), Levinson (1978), Missirian (1980), and Phillips (1977). For the most part the authors of these papers collected their data through the methods of intensive interviews and/or lengthy questionnaires. Importantly, there is much agreement among them as to what functions and characteristics represent mentoring. Second, papers that reviewed existing literature on men- 


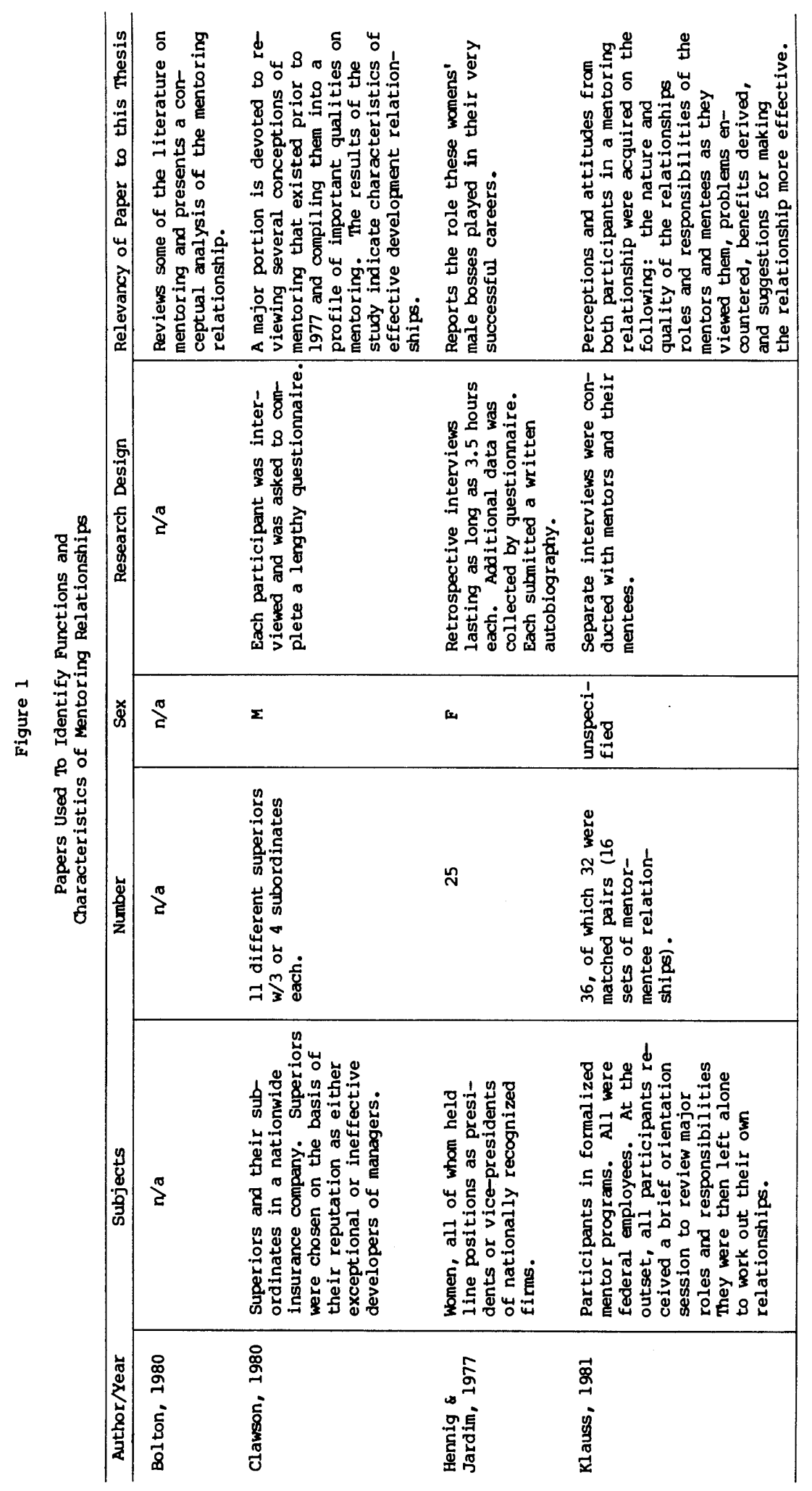




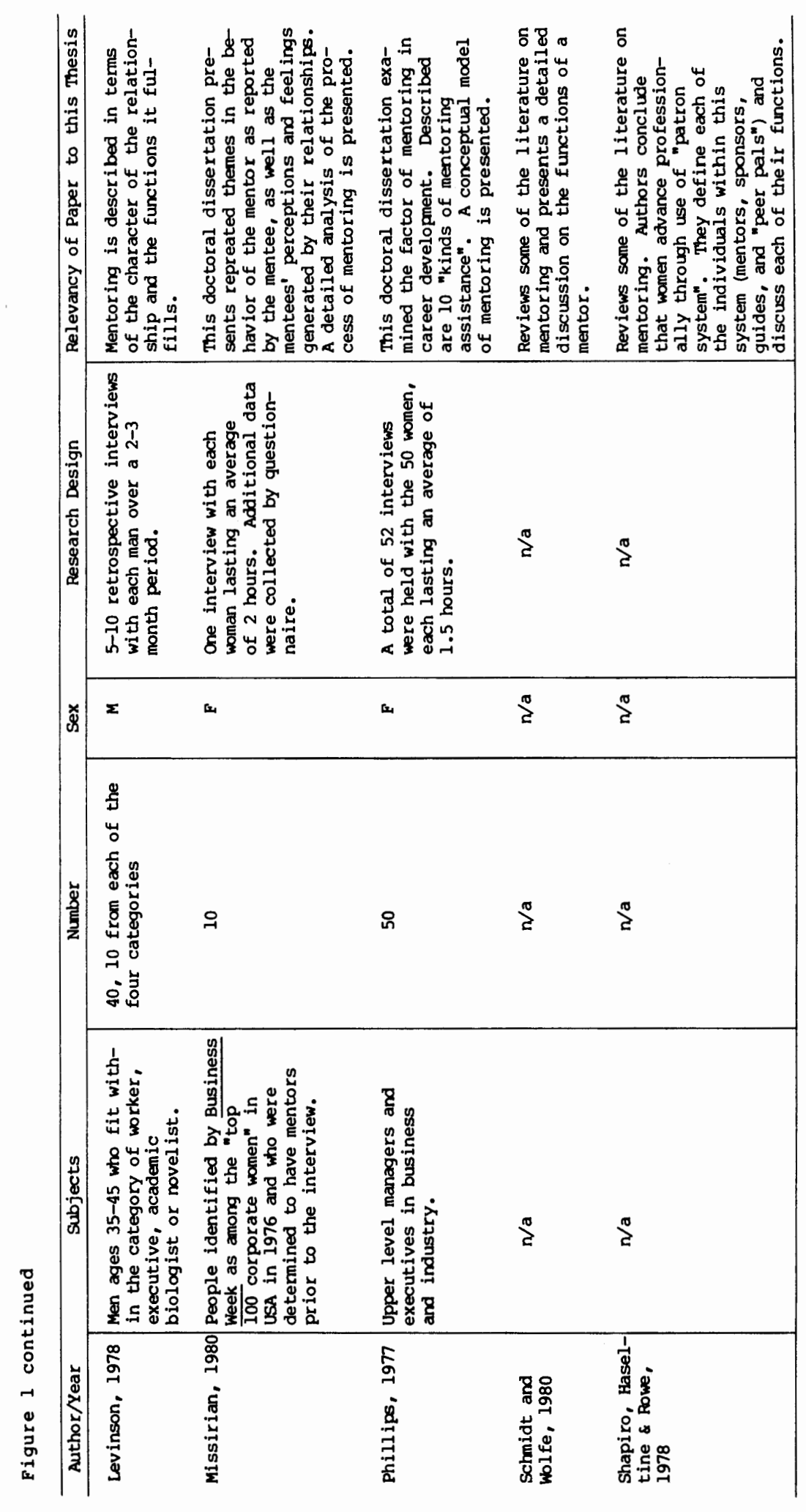


toring for the purpose of conceptualizing the topic were included for use in this survey. These papers include: Bolton (1980), Schmidt and Wolfe (1980), and Shapiro, Haseltine and Rowe (1978). Basically, these reviews reported the kinds of functions and characteristics that had already been identified in surveying the previously mentioned studies.

There are a considerable number of other papers available that discuss mentoring. However, these papers are not empirically based, and were excluded for that reason (e.g., Burrow, 1980; Cook, 1979; Halatin, 1981; Marsicano, 1981; Merkin, 1977; Thompson, 1976). A review of them found that they generally presented variations of the functions and characteristics that were identified in surveying the nine papers in Figure 1.

Functions and Characteristics of the Mentoring Relationship Listed

Compiling an exhaustive list of functions and characteristics was accomplished in the following manner: All studies represented in Figure 1 were carefully read and reviewed. Each was then reviewed again and carefully gone over for the single purpose of identifying what the author(s) concluded were features of the mentoring relationship. Each phrase or idea that implied an attempt at defining or describing a characteristic or function of mentoring was recorded on a $3 \times 5$ card. The author's name 
served as a heading for the card. For example, on a card entitled "Clawson (1979)" was written the statement "both mentor and protege have high levels of respect for one another"; on another card, entitled "Levinson (1978)", the statement "mentor fosters development by believing in mentee, sharing his or her dream". A total of 117 statements resulted. Statements referring to similar ideas were sorted accordingly and eventually rewritten as one statement. The result of the entire procedure was a collection of 30 statements, each describing one property of a mentoring relationship. Taken together they represented a listing of all the properties of an ideal mentoring relationship.

Analysis of the statements showed that each could be subsumed under one of four general headings. These four general headings appear as points I, II, III and IV in Figure 2. The statements themselves appear as subpoints in Figure 2. The first identifying feature listed in Figure 2 refers to the fact that a mentor is a person with more status than the mentee. Here status is meant to reflect not only the mentor's position of greater responsibility (generally) but more importantly that he or she has access to important resources that a mentee could respect and aspire to. These resources may include expertise, influence, knowledge, and opportunities. Missirian (1980) concluded that the "power" of the mentor (possession of 
personal and material resources) was a central element in distinguishing mentoring relationships from other kinds of supportive relationships. A number of other researchers (e.g., Levinson, 1978 and Phillips, 1977) have referred to the mentor as a person of superior knowledge and experience.

The second set of statements appearing in Figure 2 refers to the fact that a mentor takes an active (versus passive) role in the career development of a mentee. The mentor performs a number of functions (subpoints a-d) on behalf of the mentee, all seemingly without asking or expecting the mentee to reciprocate. In this sense the relationship can appear one way. It is important to remember that the list describes an ideal mentoring relationship. So while it is argued that in a true mentoring relationship the mentor does indeed perform a number of functions on behalf of the mentee, he or she does not necessarily perform each and every one that appears in Figure 2. The issue of exactly how many he or she should perform to be considered a true mentor is addressed later in this chapter.

The third set of statements in Figure 2 define an additional outstanding characteristic of the mentoring relationship: there are high levels of emotional involvement on the part of both participants. As can be seen from the supportive statements (a-e) a wide range of emotion 
Figure 2

Defining Mentoring in Terms of the Character of the Relationship and the Functions it serves

I. IN A MENTORING RELATIONSHIP THE MENTOR HAS HIGHER STATUS THAN THE MENTEE. THIS STATUS IS IN TERMS OF THE RESOURCES TO WHICH MENTORS HAVE ACCESS, I.E., EXPERTISE, INFLUENCE, INFORMATION AND OPPORTUNITIES (LeVinson, 1978; Missirian, 1980; Phillips, 1977).

II. IN A MENTORING RELATIONSHIP, THE MENTOR ACTIVELY (VERSUS PASSIVELY) PERFORMS A WIDE RANGE OF FUNCTIONS FOR THE MENTEE, SOME OF WHICH INCLUDE THE SHARING OF RESOURCES.

a. Mentors provide "Love"--expressions of affectionate regard, warmth, or comfort.* Mentors:

1. genuinely care about mentees as persons. Mentors take an interest in the feelings, concerns and life of their mentees (Phillips, 1977; Schmidt \& Wolfe, 1980).

2. reassure, encourage and support mentees during difficult or stressful times (Bolton, 1980; Hennig\& Jardim, 1977; Missirian, 1980; Phillips, 1977; Schmidt \& Wolfe, 1980).

b. Mentors provide "status"--evaluative judgements that convey prestige, regard, esteem. Mentors:

1. make mentees feel they are someone able, talented, someone whose ability is worth cultivating (Clawson, 1980; Levinson, 1978; Missirian, 1980; Phillips, 1977).

2. make mentees feel they belong, are accepted. Mentors welcome mentees into the profession as promising newcomers. Mentors encourage others to accept mentees as okay (Bolton, 1980; Levinson, 1978; Misirian, 1980; Phillips, 1977; Shapiro, Haseltine \& Rowe, 1978).

c. Mentors provide "Information"--advice, opinions, instruction, or enlightment. Mentors:

* These categories and their definitions are adapted from Foa \& Foas' (1976) chapter titled Resource Theory of Social Exchange. 
Figure 2 continued

1. instruct mentees on technical aspects of the job. Mentors teach job skills and enhance mentee's intellectual knowledge of the job (Bolton, 1980; Clawson, 1980; Hennig \& Jardim, 1977; Levinson, 1978; Missirian, 1980; Phillips, 1977; Schmidt \& Wolfe, 1980).

2. provide advice and guidance to mentees on how to solve problems (Bolton, 1980; Klauss, 1981; Levinson, 1978; Phillips, 1977; Schmidt \& Wolfe, 1980).

3. offer feedback. Mentors offer constructive criticism, praise to mentees (Bolton, 1980; Klauss, 1981; Levinson, 1978; Phillips, 1977; Schmidt \& Wolfe, 1980).

4. set high professional standards and/or performance standards mentees are encouraged to follow. Mentors emphasize competence and excellence as qualities to strive for (Clawson, 1980; Missirian, 1980; Phillips, 1977; Schmidt \& Wolfe, 1980).

5. serve as role models or examples for mentees to follow (Bolton, 1980; Clawson, 1980; Klauss, 1981; Levinson, 1978; Missirian, 1980; Phillips, 1977; Schmidt \& Wolfe).

6. share information with mentees on the norms and standards of their shared profession and/or work setting, e.g., mentors share information on political systems that operate (Clawson, 1980; Phillips, 1977; Schmidt \& Wolfe, 1980).

d. Mentors provide "Services"--activities that affect the body or belongings of a person and that often constitute labor for another. Mentors:

1. give mentees challenging and meaningful work to do. Mentors give mentees opportunities to do responsible work that provides mentees with chance to show what they can do. Mentors ask mentees thoughtful, perceptive questions thereby presenting a challenge to mentees to think more clearly and creatively (Bolton, 1980; Clawson, 1980; Missirian, 1980; Phillips, 1977; Schmidt \& Wolfe, 1980). 
Figure 2 continued

2. help mentees with career planning. Mentors discuss career move strategies with mentees, encourage them to attend seminars, classes, join professional organizations for sake of career (Clawson, 1980; Hennig \& Jardim, 1977; Klauss, 1980; Levinson, 1978; Missirian, 1980; Phillips, 1977; Schmidt \& Wolfe, 1980).

3. help mentees with career moves. Mentors hire and/or promote mentees, use their influence and reputation to facilitate entry and advancement in the profession by making personal recommendations, acting as sponsor, or using connections to promote professional development of mentees (Clawson, 1980; Hennig \& Jardim, 1977; Klauss, 1981; Levinson, 1978; Missirian, 1980; Phillips, 1977; Schmidt \& Wolfe, 1980).

4. give mentees visibility, i.e., mentors include mentees in important discussions with other VIP's, introduce mentees to important others, encourage mentees to participate in key presentations, meetings, conferences. Mentors make sure mentees receive recognition for their work (Klauss, 1981; Missirian, 1980; Phillips, 1977).

5. act as protectors. Mentors shield mentees from unreasonable or unwarranted criticism and/or act as buffers between hostile individuals and mentees (Hennig \& Jardim, 1977; Missirian, 1980; Shapiro, et al., 1978).

III. IN A MENTORING RELATIONSHIP, THERE IS A HIGH (VERSUS LOW) DEGREE OF. EMOTIONAL INVOLVEMENT AMONG THE PARTICIPANTS.

a. There are mutual feelings of respect, admiration, trust, appreciation, and gratitude between mentors and mentees (Clawson, 1980; Hennig \& Jardim, 1977; Levinson, 1978; Missirian, 1980; Phillips, 1977).

b. The participants are emotionally close. They value the rewards of the personal nature of the relationship, not just the functional rewards (Clawson, 1980; Missirian, 1980; Phillips, 1977).

c. The level of affection in the relationship has been described as similar to that between parent and child (Clawson, 1980; Hennig \& Jardim, 1977; 
Figure 2 continued

Levinson, 1978; Phillips, 1977; Shapiro, et al., 1978 ).

b. Feelings of isolation from others (e.g., coworkers, social contacts) on the part of mentees are not uncommon (Hennig \& Jardim, 1977; Missirian, 1980). Feelings of envy, inferiority, resentment and intimidation may be experienced by mentees (Clawson, 1980; Levinson, 1978; Missirian, 1980).

e. It is an unselfish relationship. There is a sense of reciprocity and willingness to share information and exchange favors. It is the best interests of one another that seem to be at the heart of this unselfishness (Clawson, 1980; Klauss, 1981; Levinson, 1978; Phillips, 1977).

IV. IN A MENTORING RELATIONSHIP, DEVELOPMENT OF MENTEE'S PERSONAL AND PROFESSIONAL SELF-CONCEPT IS FACILITATED.

a. Mentees increasingly experience themselves as capable, autonomous individuals (Levinson, 1978). They become increasingly self-assertive (Missirian, 1980). Mentors play a role in this process by:

1. permitting mentees to challenge their point of view without becoming defensive or competitive (Missirian, 1980; Phillips, 1977).

2. allowing mentees the freedom to make mistakes; to learn by trial and error without fear of serious repercussions for failures (Clawson, 1980; Missirian, 1980).

3. demanding high standards of performance but not to the point where mentees fail (Clawson, 1980; Missirian, 1980).

4. pointing out to mentees their strengths, abilities, talents. Mentors promote feelings of competence and high self-esteem (Hennig \& Jardim, 1977; Levinson, 1978; Missirian, 1980; Phillips, 1977; Schmidt \& Wolfe, 1980).

5. encouraging mentees to set high goals for themselves and have high expectations of themselves (Missirian, 1980; Phillips, 1977; Schmidt \& Wolfe, 1980). 
Figure 2 continued

b. There are high levels of identification between mentors and their mentees. Each sees something in the other that reminds them of themselves in some way, e.g., similar goals, backgrounds, beliefs (Clawson, 1980; Levinson, 1978).

c. Mentees internalize the admired qualities (values, attitudes, goals) of mentors (Levinson, 1978;

Missirian, 1980; Schmidt \& Wolfe, 1980). Levinson. (1978) says mentees are thus better able to learn from themselves. 
is possible. Missirian (1980) wrote that emotional involvement, or ego involvement, on the part of the participants was the most outstanding feature of the relationship that she observed. She wrote,

In reviewing all of the interviews ..., one thing stands out: The emotional involvement in a true mentoring relationship goes far beyond the utility of the relationship in terms of sponsorship or career modeling. A caring develops which makes the relationship at once stronger in every respect and at the same time more tenuous. Each partner invests so much of self that each becomes the more vulnerable to the other.

The fourth distinguishable set of statements appearing in Figure 2 refers to the mentoring relationship as one that facilitates the development of the mentee's personal and professional self-concept. Levinson (1978) is the one individual most responsible for portraying the mentor as important to the mentee's personal as well as professional development. Levinson sees the mentor as a transitional figure, guiding the younger person in his or her transition from young adulthood to middle adulthood. The means through which the mentor accomplishes this have been suggested by Levinson and others. For example, Phillips (1977) found that mentors encourage their mentees to set high goals for themselves and to see themselves as capable of achieving those goals. Hennig and Jardim (1977) concluded that the mentoring experience of each of their women subjects "provided her with the extra confidence she 
needed to take on new responsibilities, new tests of her competence and new positions" (p. 157).

Assessing prevalence of Mentoring: The Career Support Scale

This chapter has described how the existing literature on mentoring was surveyed to identify functions and characteristics of the mentoring relationship. Figure 2, which groups the functions and characteristics under four headings presents the results of this survey. Figure 2 thus formed the basis for operationalizing true mentoring. The information presented suggests that a relationship can be identified as true mentoring when an individual (the mentee) reports receiving a number of provisions from another with superior resources (the mentor) in the course of developing his or her career. Further, the mentee in a mentoring relationship will report high levels of emotional involvement with the mentor. Lastly, a mentee will report an effect by the mentor on his or her personal as well as professional development. The extent to which each of these features is present in the relationship further determines whether or not the relationship is a true mentoring relationship. One would expect a true mentoring relationship to be strong in each area, but not necessarily to display all of the qualities possible in each area. For this study, the Career support scale (CSS) was designed in order to determine the extent to which each feature, and 
thus the extent to which true mentoring was present in each subject's career support system. The css contained four subscales: RESOURCES, PROVISIONS, EMOTION and SELF-CONCEPT. These subscales were constructed by rephrasing each statement that appeared in Figure 2 into a short descriptive phrase to which subjects could relate, for example, "This person assists you in learning the technical aspects of your job" (from point II), and "This person has had a positive influence on your self-confidence" (from Point IV). The result was four groups of statements or four subscales, each subscale representing one of the four general features of a mentoring relationship.

Responding to the scales by the subject involved two steps. First, subjects were asked to list up to five people they felt had played a positive role in the development of their career. Second, the subjects were asked to indicate the extent to which each item on the subscale was applicable to each person they listed. (See questions Nos. 1, 6A and 10 on the "Career Support Survey", Appendix A.) Subjects used a five-point scale to do so. On the scale subjects used, a response of " 5 " indicated the statement was "very descriptive" or "extremely frequently" true of the relationship. A response of "4" indicated the statement was "mostly descriptive" or "often" true of the relationship. A response of "3" indicated the statement was "somewhat descriptive" or "sometimes" true of the re- 
lationship and so on, with the response of "l" indicating the phrase was "not at all descriptive" or "never" true of the relationship.

Thus, each item in each of the four scales had a value of 1 to 5 assigned to it by the subject. All items representing a particular subscale were summated. Thus, four scores were obtained for each person the subject listed. The scores ranged from 0-75 on the pRovisions scale (a 15-item scale), 0-25 on the EMOTION scale (a 5item scale), $0-40$ on the SELF-CONCEPT scale (an 8-item scale) and 0-5 on the RESOURCE scale (a single item scale). Each score represented the extent to which one of four general features of the mentoring relationship was present in that relationship. For purposes of discussion only, an average score should be thought of as having been calculated for each subscale; so that each subscale now has a score of 0 to 5. Doing so greatly simplifies the discussion that follows. The discussion involves the development and application of the criterion for determining who the mentors were.

The criterion used in this study for determining whether or not a person the subject listed was a mentor was an arbitrarily drawn one. It was based on the following: Since one would not expect even a true mentoring relationship to display all the functions and characteristics listed in Figure 2 (and thus score a perfect 5 on each 
scale) a score of something less than "5" was chosen as the criterion for determining whether or not a person listed was a true mentor. At the same time, it is argued that a true mentoring relationship would display at least a majority of those functions and characteristics in each of the groups (and thus have an average score of better than "3" on each scale). Therefore, those subjects who listed persons scoring an average of 3.5 or better on each of the four scales were determined to have a mentor. (In real terms, this meant a person had to have a score of 53 on the PROVISIONS scale, 18 on the EMOTIONS scale, 28 on the SELFCONCEPT scale and four (4) on the RESOURCE scale to be considered a mentor.) 
CHAPTER $\mathrm{V}$

SAMPLE SURVEY

In the previous chapter, a literature survey was used as the method to address the first of the three goals of this study (see Chapter III for a presentation of those goals). In the following chapters, data collected from a sample survey were used as the method to address the second and third goals of this study. This chapter presents the procedures followed in conducting that sample survey. The survey sample and survey instrument are described. Subject response to the survey is presented next, followed by a description of how the data collected were analyzed. Also included is a discussion of the representativeness of the sample. Finally, the demographic characteristics of the survey respondents are presented.

\section{Procedures}

Sample. The subjects of this study are women laywers who are members of the Multnomah Bar Association. The bar association, located in the State of Oregon, has a membership estimated at 2,300 persons. It is not known exactly how many of these persons are women, however it is estimated that 300-400 of them are women. To select the 
sample, the membership list of the association (which does not identify the sex of the members) was surveyed and note made of all female-sounding first names. All names that could be interpreted as female were selected as subjects; 361 names were so identified.

Survey Instrument. The survey instrument used to collect data on the issues addressed in this study consisted of two parts. The major portion of the survey instrument was the Career support scale. This scale was described in detail in the previous chapter. The second part of the survey was a series of questions on demographics. These questions were included for the following reasons: (a) to assess the representativeness of the sample to the study population by comparing responses of those who answered when first contacted to responses of those who responded only after further contact; (b) to profile the typical subject of this study; and (c) to relate the results of this study to the nature of the sample.

The questionnaire was pretested by administering it via an informal interview to five women lawyers who were members of a county bar association in Washington state. Upon being administered the questionnaire, the women were asked about clarity of the questions, their reaction to its length, and their general comments on its content. Certain modifications were made and a final version as well as a 
cover letter were assembled. A copy of the final instrument and cover letter appear in Appendices $A$ and $B$, respectively. The questionnaire, cover letter, informed consent form (Appendix $\mathrm{C}$ ), and a stamped return envelope were mailed to each of the 361 subjects.

\section{Subject Response}

From the initial mailing 141 questionnaires (398) were returned. of these, 115 (32\%) were usable. The rest, $26(78)$, were marked "undeliverable" or were returned by males. This left 221 nonrespondents. Nonrespondents were contacted a second time either by phone or by a second letter approximately three weeks after the first mailing was sent. For those for whom no telephone number was available (44), a second letter, questionnaire and stamped return envelope were mailed. This mailing resulted in seven ( 38 of the nonrespondents) replies. For those for whom a phone number was available (177) 138 were reached. This contact resulted in 49 (22\% of the nonrespondents) replies. Approximately three weeks after the second contacts were made, follow-up postcards were sent to those nonrespondents who had been reached by phone and who had indicated they would be completing and returning the questionnaire. This contact resulted in an additional 14 (6\% of the nonrespondents) responses. Table I summarizes the response rate for the survey. 
TABLE I

SURVEY RESPONSE

Number of Questionnaires Mailed

361

Number of Respondents

lst mailing 115 completed surveys

185

2nd contact 56 completed surveys

3 rd contact 14 completed surveys

Number Returned Marked "Unknown", "Male"

Adjusted Sample Size (number mailed minus number returned marked "Unknown", "Male")

Total Response Rate (number of respondents divided by adjusted sample size)

Analysis of Data

Questionnaire responses were analyzed by computer. The statistical Package for the Social Sciences (SPSS) computer program was used to compute descriptive statistics -- basic frequencies and measures of central tendency -- on the data. Pearson correlation coefficients and partial correlation coefficients were calculated to examine relationships between several variables of interest to this study. A cronbach's alpha reliability coefficient was computed for each of the subscales constructed to measure career support. A number of t-tests were conducted to explore differences on outcome variables based on group membership. 
Representativeness of Sample

This study was successful in encouraging a large number of non-respondents to become respondents as a result of contacting them a second and occasionally a third time (see Table I). Because the numbers involved were large, it was decided to compare the responses of these "later" respondents $(n=70)$ to the responses of the 115 "initial" respondents (those who returned the survey after the first contact). If it were found that the two groups differed in some way, it would have meaning to the interpretation of this study's findings. Also, it was felt that this comparison could be used to assess the representativeness of the sample to the population from which it was drawn. If those women in the "later" group, who were at one time nonrespondents, were not different from those in the "initial" group, we might assume that both groups are not different from the nonrespondents. Thus, descriptive statistics were computed for each of the two groups on the following demographic characteristics: age, marital status, number of children, race, religion, years since law school graduation (which, when subtracted from the date 1982, was used as a measure approximating the number of years the subject had worked in the law profession), number of years at current job position, and income. To supplement the descriptive statistics, a series of statistical tests of difference were conducted on the two 
groups for each of the characteristics above. These tests showed no significant differences between the two groups. Because of these insignificant results, the statistics for each group are not reported here. Rather, they have been summarized and placed in Appendix D. Further, because of these results, the two groups of respondents have been treated as one group in all future data analyses.

A further test of the representativeness of this sample to the study population was conducted. specifically, data were available for all but a few respondents and for all but a few nonrespondents to this study on the year each became a member of the oregon state Bar. This information was used to estimate the number of years in the field for each woman. It was found that a respondent averaged 4.1 years $(S D=6.5)$ on this variable. The average for a nonrespondent was not statistically different $(X=4.6, S D=6.5)$. Thus, it $c a n$ be concluded that the level of experience in law observed for subjects sampled is representative of the level of experience for the population of interest.

The findings of this study concerning number of years in the profession are consistent with a recent report in the American Bar Association Journal (Fossum, 1981). According to this article, the number of women graduating from law school in 1980 was 460 percent higher than in the early 1970's. The number of women lawyers has more than 
doubled in the period from 1975 to 1979 (from 26,000 to 59,000), the author reported. The data for subjects of the present study reflect this trend.

In summary, no differences were found between the two subgroups of respondents on any demographic variables; nor were any differences found between respondents and nonrespondents on the variable of number of years in the profession. Based on these results, it was assumed that the sample could be considered representative of the study population. In addition, there is no evidence to suggest that this sample is not representative of women lawyers in general. The sample is profiled in the following section.

Demographic Characteristics of Survey Respondents

Age. The women in this study ranged in age from 25 years to 74 years. The mean age was $34(S D=7.6)$. The median age was 32. Table II shows the distribution of ages in this sample.

TABLE II

DISTRIBUTION OF AGES

\begin{tabular}{ccc}
\hline Age & $\begin{array}{c}\text { Number of Women } \\
\text { of This Age }\end{array}$ & \& of Total \\
\hline $25-29$ & 54 & 29 \\
$30-34$ & 71 & 38 \\
$35-39$ & 41 & 22 \\
$40-44$ & 8 & 4 \\
45 and older & 12 & 7 \\
\hline
\end{tabular}


Martial status. A majority of the women in this study were married (54\%); a smaller group (8\%) reported themselves "living as married". One out of five (20\%) have never been married. Other categories represented were: divorced (15\%), separated (2\%), and widowed (1\%).

Number of Children. Most of the women (66\%) have never had any children. Of those with children, 12 percent reported one child, 15 percent two children, three percent three children, and the rest (4\%) reported four children.

Race. Of the 185 women subjects, 181 (98\%) were white. The other races represented were Asian American (2\% of the sample) and other (less than 18 of the sample).

Religion. The largest group of women, 41 percent of the sample, reported themselves as unaffiliated. Protestants numbered 31 percent of the sample. Jewish and Catholic persons each numbered 12 percent of the sample; the category of other represented the rest (3\%).

Years Since Law School Graduation. The data collected on law school graduation date was used to estimate the variable of number of years each woman has been in the field of law. As can be seen in Table III, over 80 percent of the sample has graduated from law school since 1975, with the largest group (2l\%) graduating in 1980. This indicates a mean number of years in the profession of 4.9 years $(S D=6.7)$; the median was 3.3 years. The range was less than one year to 48 years. 
TABLE III

YEAR OF LAW SCHOOL GRADUATION

\begin{tabular}{ccc}
\hline $\begin{array}{c}\text { Year of } \\
\text { Graduation }\end{array}$ & $\begin{array}{c}\text { Number of } \\
\text { Women }\end{array}$ & \% of Total \\
\hline 1974 or before & 23 & 12 \\
1975 & 9 & 5 \\
1976 & 17 & 9 \\
1977 & 10 & 5 \\
1978 & 29 & 16 \\
1979 & 27 & 15 \\
1980 & 38 & 21 \\
1981 & 27 & 15 \\
1982 & 5 & 3 \\
\hline
\end{tabular}

Place of Work. The majority of women in this sample (398) work as associates in private practices. The next largest group are solo-practitioners. Table IV gives the distribution of women by current career position.

Number of Years in Current Position. On the average, the women in this sample have been at their current job for 2.2 years. The median in this case is 1.6 years. The range is less than one year to 30 years. Most of the women (56\%) have held their current positions for from six months to two years. Only 27 percent have been at their current job for more than two years. 
TABLE IV

CURRENT WORK POSITION

\begin{tabular}{lcc}
\hline \multicolumn{1}{c}{$\begin{array}{c}\text { Position or } \\
\text { Place of Work }\end{array}$} & $\begin{array}{c}\text { Number of Women } \\
\text { in this Position }\end{array}$ & $\begin{array}{c}\text { \% of } \\
\text { Total }\end{array}$ \\
\hline Associate in a Private & & \\
$\quad$ Practice & 72 & 39 \\
Partner in a Private & 13 & 7 \\
$\quad$ Practice & 32 & 18 \\
Solo-Practitioner & & 5 \\
Law Clerk/Legal & 9 & \\
$\quad$ Researcher & 13 & 7 \\
Federal, State, County & 13 & 9 \\
$\quad$ or City Government & 17 & 5 \\
Private Business & 9 & 2 \\
Legal Aid & 4 & $<1$ \\
ther & 1 & \\
Unemployed & & \\
Retired & & \\
\hline
\end{tabular}

Income. Subjects were asked to report only the income they derived directly from their practice in the legal profession. The results showed an average income of $\$ 20,001$ to $\$ 25,000$. The range was from $\$ 0-\$ 5,000$ to more than $\$ 55,001$. The survey instrument did not ascertain whether the earnings resulted from full- or part-time positions. Table $V$ shows the range of salaries for women in this sample. 
TABLE V

INCOME

\begin{tabular}{lcc}
\hline Salary Range & $\begin{array}{c}\text { Number of Women } \\
\text { in this Range }\end{array}$ & $\begin{array}{c}\text { \% of } \\
\text { Total }\end{array}$ \\
\hline$\$ 0-\$ 10,000$ & & \\
$\$ 10,001-\$ 20,000$ & 4 & 16 \\
$\$ 20,001-\$ 30,000$ & 59 & 24 \\
$\$ 30,001-\$ 40,000$ & 36 & 32 \\
$\$ 40,001-\$ 50,000$ & 7 & 20 \\
More than $\$ 50,001$ & 7 & 4 \\
& & 4 \\
\hline
\end{tabular}


CHAPTER VI

\section{PREVALENCE OF MENTORING AND OTHER \\ FORMS OF CAREER SUPPORT}

This chapter presents the results of the sample survey as they relate to the second goal of this study. The second goal of this study, as described in chapter III, was to assess the prevalence of mentoring (as defined in this study). A part of this second goal was to identify a second group of career-supported women. A woman in this group, the literature suggested, would not have a mentor but would have a group of supportive individuals. who together were providing her with the kind of help and support found in a mentoring relationship. Both a group of mentored women and a group of these latter women were identified in this study. In addition, other forms of career support were identified and are described below.

Assessing Type of Career Support With Career support Scale

The "ideal" career support has been described in this paper as a mentor. A true mentor was conceptualized as (a) being a person of superior status (in terms of access to resources), (b) performing a number of functions on behalf of the mentee, (c) providing emotional support to the 
mentee, and (d) providing direction for the development of a positive self-concept on the part of the mentee. The subscales of RESOURCES, PROVISIONS, EMOTION and SELF-CONCEPT were constructed to measure the extent to which each respective feature was present in each of the relationships listed by the subject. Data collected from the scale were used to assess the prevalence of true mentoring in this sample and also to assess the prevalence of relationships in this sample that contained only individual elements of a true mentoring relationship.

Reliability analyses of each of the subscales showed a Cronbach's alpha of .94 for the PROVISIONS scale, .82 for the EMOTION scale, .90 for the SELF-CONCEPT scale, and 1.0 for RESOURCE scale (a single item scale). Each of these correlations indicate a high degree of internal consistency of items within each of the subscales, and thus it can be assumed the items within each scale are measuring the same general construct.

For the most part, if subjects gave a support person a high score on one of the four scales, she also gave that person high scores on the other three scales. Likewise, low scores on one scale were related to low scores on the others (see Table VI). This indicates that subjects viewed the persons listed as low to high sources of career support overall and not as sources of individual forms of help. 
TABLE VI

MEAN RELATIONSHIPS BETWEEN SCALES

\begin{tabular}{lcccc}
\hline \multicolumn{1}{c}{ SubSCAIE } & PROVISIONS & EMOTION & CONCEPT & RESOURCES \\
\hline & & .83 & .83 & .73 \\
PROVISIONS & 1.0 & $(.06)$ & $(.08)$ & $(.07)$ \\
EMOTION & & .91 & .55 \\
& & 1.0 & $(.04)$ & $(.12)$ \\
SELF CONCEPT & & & .52 \\
RESOURCES & & 1.0 & $(.15)$ \\
\end{tabular}

Note. It was possible for a subject to complete each subscale as many as five times (once for each person listed). These coefficients represent the average relationship between the scales. Standard deviations appear in parentheses. All correlations were significant at the .001 level.

Prevalence of Mentoring

Number of Mentors. The Career support Scale and the criteria established in this study for determining how many, if any, of the women surveyed have been in receipt of true mentoring has been presented in detail in Chapter IV. Using those criteria, 60 women, 35 percent of the total sample, were found to have at least one true mentor. About 13 percent of the total sample, or 40 percent of those with a mentor, were found to have more than one mentor. Table VII shows the breakdown of the number of mentors per subject. 
TABLE VII

DISTRIBUTION OF MENTORS

\begin{tabular}{ccc}
$\begin{array}{c}\text { Number of } \\
\text { Mentors }\end{array}$ & $\begin{array}{c}\text { Number of } \\
\text { Subjects } \\
(\mathrm{N}=171)\end{array}$ & $\begin{array}{c}\text { o } \\
\text { subjects }\end{array}$ \\
\hline & 112 & 65 \\
1 & 36 & 21 \\
2 & 19 & 11 \\
3 & 2 & 1 \\
4 & 2 & 1 \\
5 & 1 & $<1$ \\
\hline
\end{tabular}

Mentor Characteristics. For those subjects who were identified as having true mentors by the standards set in this paper, their mentors were most often a boss or supervisor (in legal field). Of the 60 women with mentors, 34 of them had as a mentor at least one boss or supervisor. Twenty-two women had as a mentor at least one colleague. Thirteen of the women had as a mentor their spouse/colleague and 10 women had at least one mentor from a variety of other categories. (A list of the categories of career supports mentioned by subjects of this study appears in Appendix E.)

The sex of the mentors was most often male. Eightytwo percent of the women with mentors had at least one male mentor. Thirty percent of the women were mentored by a woman at least once. of the 93 mentors identified, 71 (76\%) were male, $22(24 \%)$ were female. 
Mentors were, on the average, 8.2 years older $(S D=10.1)$ than their mentees. Mentors ranged from ten years younger to 35 years older than their mentees.

The persons who scored as mentors were listed by the subjects as being a source of support for 5.6 years (SD = 4.8), on the average. The relationships ranged in length from one to 20 years. These results are important given that the mean number of years in the profession for those women with mentors is 4.6 years $(S D=5.3)$. This indicates that a number of women had mentors before they graduated from law school. In fact, 45 percent of the women reported the person identified by this study as their mentor to be an important source of support before law school graduation. This meant that 55 percent of those with mentors acquired their mentor after law school. Lastly, 56 of the 60 women with mentors report these persons as either "presently a source of help/support" $(n=46)$ or "still helpful/supportive but not to the extent they were in the past" $(n=10)$. The four remaining women reported their relationships to be "helpful/supportive in the past but no longer so". These relationships ranged in length from three to twenty years. The mean length was 9.3 years $(S D=6.0)$. This indicates that 93 percent of the subjects identified as having a mentor in this study have a current mentor, regardless of whether she acquired that mentor before or after law school. 
Prevalence of Mentoring Discussed. The percentage of mentored women identified in this study is lower than percentages reported in other studies of professional women. Three possible reasons for this difference were explored. The first involved the population surveyed. Most studies on women and mentoring have surveyed women managers and/or executives (e.g., Fitt \& Newton, 1981; Hennig \& Jardim, 1977; Missirian, 1980; Phillips, 1977; Shockley \& Staley, 1980). Other studies have surveyed women in education administration (e.g., Bova \& Phillips, 1981; Erickson \& Pitner, 1980; Moore \& Sangaria-Danowitz, 1979) and graduate education (Cameron, 1981; Kirchner, 1969). This author is not aware of any studies of women lawyers and mentoring. The phenomenon of mentoring is a part of the legal profession, however. Epstein (1970) indicated that the "old-boy network" is as old as the field of law itself and proceeded to discuss the need for women to become a part of that network. In addition, twelve subjects of this study mentioned a mentor in their written comments. At no time did any subject indicate that the concept did not exist in her profession. Undoubtedly some aspects of the relationship are peculiar to the field in which it occurs. It is argued, however, that the four features of the relationship that have been described in this paper (see Chapter IV) are a part of every mentoring relationship, regardless of profession. Johnson (1980) has 
said "The mentor's role is not in pulling people up the career ladder, but in developing the individual." This statement reflects the kind of relationship this study has defined as true mentoring. It is assumed such relationships exist in all fields. Based on the above, the nature of the population was rejected as the explanation for the observed rate of mentoring in this study.

A second possible explanation considered, related to the nature of the sample. The average age of a subject in this study ( 34 years) and her average length of time in her profession ( 4.9 years) were low when compared to women in other studies on women and mentoring mentioned above. For example, the mean age of the subjects in Phillips' (1977) study was 56; in Missirian's (1980) study, the mean age was 47.8. In Hennig and Jardim's (1977) report, the subjects were all approximately 50 years old at the time each was interviewed. Explored, therefore, was the possibility that the low rate of mentoring observed in this study was due to the fact that the younger and "newer" women to the profession had not had an opportunity to develop the type of relationship assessed in this study. If this were true, it would be expected that age and number of years in the profession would be positively correlated with having a mentor (a dichotomous variable). However, this was not the case. Correlational analyses showed an almost zero relationship between having a mentor and age $(r=.05)$ and 
between having a mentor and number of years in the profession $(r=.01)$. A t-test comparing the group of women at or under the mean age (34) to the group of women over the mean age on the variable of having a mentor showed no significance. The same test was run for the variable of number of years in the profession on having a mentor. No significant results were found. These results are not surprising given the earlier reported results that 45 percent of the women with a mentor had that mentor before law school graduation and that 93 percent of the mentoring relationships identified are current. These results indicate that the women with mentors in this study are of all ages and levels of experience in their profession. Thus, it was concluded that the age of the sample and their length of time in the profession were not the predictors of the rate of mentoring observed in this study.

A third possible explanation involved the difference in the method used to assess mentoring in this study compared to the methods used in other studies. The method used in this study to assess the prevalence of true mentoring was deliberately different from the more "traditional" methods which were described in Chapter II. (See section entitled "How Common is Mentoring?" in Chapter II for a discussion and examples of these methods.) It was concluded in Chapter I that use of these "traditional" methods resulted in variable rates of mentoring being 
observed across studies. The percentage of subjects reporting mentors in previous studies ranged from 47 percent to 92 percent with a median for the different studies of 66 percent. In order to estimate the effect of using different methods, subjects of this study were asked to respond to a traditional type question in addition to responding to the Career support scale. The question presented to the subjects of this study appeared as the last question on the survey instrument. It read:

Individuals who take a personal interest in helping a less experienced person advance in their career have been called "mentors". Mentors "teach the ropes" of a profession, act as sponsors and guides for the mentee, and serve as role models. Have you ever had a mentor?

$$
\text { Yes No }
$$

If yes, how many?

While it is not possible to know how responses to this question were influenced by responses to previous items on the questionnaire, the results are nevertheless interesting and are presented below in Table VIII. It can be seen that 67 percent of the women reported at least one mentor, and that a majority reported more than one mentor.

The rate of 67 percent was compared to the rates of those studies reported in Chapter II. It was also compared to the rate of 35 percent reported earlier as the rate of "true mentoring" in this study. Based on these comparisons, it was concluded that the differences in the observed rates 
were highly likely the result of the different methodologies used to arrive at those rates.

\section{TABLE VIII}

PREVALENCE OF MENTORING AS MEASURED BY SUBJECT

RESPONSES TO A "TRADITIONAL" QUESTION ( $=182)$

Number of Mentors Number of Subjects 8 of Subjects

$\begin{array}{rrr}0 & 60 & 33 \\ 1 & 52 & 29 \\ 2 & 37 & 20 \\ 3 & 17 & 9 \\ 4 & 2 & 1 \\ \text { More than } 5 & 14 & 8\end{array}$

The difference in methods involved the different way in which mentoring was operationalized to subjects. The method used in this study to operationalize mentoring was to present to the subject for her response a list of functions and characteristics researchers have agreed are part of the mentoring relationship (Chapter IV). The method used in previous studies was to present to the subject an unscientifically-derived conception of mentoring for her response. Wrightsman (1981) has argued that this latter method does nothing to develop the concept scientifically. The fact that two different rates of mentoring were observed for the subjects of this study, using two different methods, supports Wrightsman's argument. 


\section{Identifying Career Supports other Than Mentors}

Almost two-thirds of the women in this study (658) were determined not to have mentors. It was suggested in Chapter II that those women without mentors may instead be receiving the kinds of benefits experienced in a mentoring relationship from more than one person, each providing one or more of the aspects of a mentoring relationship. A number of data analyses were done to clarify the issue.

First, it was found that an average of 3.5 persons were 1 isted as supportive by the women without mentors. (This is not significantly different from the mean number of persons listed by those in the Mentored group.) The persons listed were divided into two groups. Persons in the first group were termed " not significant sources of career support" (NtSigSup). Of course, this may not be the feeling of the subject toward this person, however, the term is used for purposes of discussion. Persons assigned to this group were those who scored less than the established criteria on all four subscales of the career support scale.

The second group were termed "significant sources of career support" (SigSup). Again, this term is for purposes of discussion and may not reflect the subject's feeling toward this person. Sigsup's are those who scored an average of 3.5 or greater on at least one of the four career support subscales. These persons are providing 
their acquaintance (the subject) with at least some of the qualities one finds in a mentoring relationship. As stated earlier a goal of this research was the identification of a group of women who were receiving all of the benefits of a mentoring relationship from a system of persons such as these sigsup's. A computer program was written to identify these "pseudo-mentored" subjects. A pseudo-mentored subject was one who did not have a mentor but who had a minimum of two Sigsup's who between them had average scores of 3.5 or better on all four career support subscales. For example, a typical woman will have listed four supports. Most likely, none of those supports had high scores on all four subscales. Possibly, however, between all four supports, scores of 3.5 or greater could be found for each scale. If so, this woman would be termed pseudo-mentored. (Appendix $\mathrm{F}$ contains an example of a typical case.) In all but a few cases, the minimum number of supports required to make up a pseudo-mentor was two (the maximum was four). Thus, in most cases, women were receiving some aspects of a mentoring relationship more than once. In all, 48 women (28\% of the sample or $43 \%$ of those without mentors) were identified as pseudo-mentored. This group is hereafter referred to as PSEUDO. This left a total of 63 women (37\% of the total sample or $57 \%$ of those without mentors) in a group called "Not Significantly Career Supported. This group is hereafter referred to as NTSIGSUP. 
Thus, as proposed, it was possible to identify two groups of career supported women--those who are experiencing true mentoring relationships (MENTOR group) and those who are receiving the benefits of a true mentoring relationship from a network of career supports (PSEUDo group). As would be expected, a third group of women were identified--those who were receiving neither of the above two forms of support (NTSIGSUP group).

It was reasonable to assume that the MENTOR group might be identified as containing two subgroups: those women with a mentor or mentors who were also being pseudomentored (M/PM) and those women with a mentor or mentors "only" (M/ONLY). An identification and description of each group was important in order to better understand the nature of the support received by the truly mentored in this study. In addition, any differences observed between the groups of $M / P M$ and M/ONLY on the outcome variables of this study would have consequences to discussions of the roles mentoring and pseudo-mentoring play in career development. of the 60 women with true mentors, 19 (328) were found that were also being pseudo-mentored. There were 1.7 mentors per subject in the mentored only group compared to 1.3 mentors per subject in the mentored/pseudo-mentored group. The mentored/pseudo-mentored group had more sigsups--those career support persons who scored an average of 3.5 or greater on any one of the four subscales of the 
career support scale--per subject than the mentored group. The numbers were 3.3 and 2.5 , respectively. Thus, it appears that 32 percent of the women with mentors are receiving somewhat more support than the other 68 percent but not a great deal more. The two groups are compared on a number of variables in later sections.

Thus, the second goal of this study has been completed; a number of career support forms were identified. In the next chapter, these forms of support are assessed for their relationship to career success and satisfaction. 
CHAPTER VII

\section{RELATIONSHIPS BETWEEN CAREER SUPPORT TYPE AND CAREER SUCCESS AND SATISEACTION}

This chapter presents the results of the survey sample as they relate to the third goal of this study. The third goal, as described in chapter III, was to explore relationships between the forms of career support identified in this study and self-perceived career success and satisfaction. The results suggest the role that mentoring plays in career development as compared to other forms of career support.

Four groups of career-supported women were identified in the previous chapter. These four groups were the Mentored only (M/ONLY) group, the Mentored/Pseudo-mentored (M/PM) group, the Pseudo-mentored (PSEUDO) group; and the Not Significantly Career supported (NTSIGSUP) group. For some data analyses, the two mentored groups were combined to make one group. This group (MENTOR) thus consisted of all women with a mentor or mentors. More will be said about this group later. In this section, the relationship of each of the groups to the outcome variables of career satisfaction and success was investigated. Six single item, Likert-type questions were employed to gather subjec- 
tive measures of career satisfaction and success for each subject. The questions and the mean score for each are presented in Table IX. The degree to which these measures were correlated with one another is presented in Table $x$.

Along with the four career support groups, a number of other independent variables were examined for relationships to the outcome variables. These included the age of the subject, the number of years she has been in the law profession (YPROF), income from her work as a lawyer, and the number of persons (0-5) 1 isted by the subject as playing an important role in the development of her career (NSUPLIST). The intercorrelations of these variables can be found in Table XIX in Appendix G.

Each independent variable and its relationship to the career satisfaction measures is shown in Table XI. Table XII shows the correlates to career success. The tables show a number of significant, although sometimes weak, relationships.

The zero-order correlations for the two mentored groups, mentored only (M/ONLY) and mentored/pseudo-mentored $(M / P M)$, indicated that stronger relationships to the outcome variables may have been masked by the common feature of both groups, namely, having a mentor. Therefore, firstorder correlations were calculated. These correlations gave a single measure of association which described the relationship between membership in the M/ONLY group and 
TABLE IX

MEAN SCORES AND STANDARD DEVIATIONS ${ }^{a}$ OF EIGHT CAREER SATISFACTION AND SUCCESS MEASURES

\begin{tabular}{cc}
\hline Measures & Mean \\
Score \\
\hline
\end{tabular}

\section{Satisfaction Measures}

1. In general, how satisfied are you with

the progress you have made in

developing your career? (SATDEV)

Range $1-6,1=$ "VERY DISSATISFIED"

$6=$ "VERY SATISFIED"

4.4

(1.3)

2. Overall, how satisfied are you with your career? (SATCAR)

Range $1-6,1=$ "VERY DISSATISFIED" $6=$ "VERY SATISFIED"

4.4

(1.2)

3. If you were to do it all again, would you choose a career in law? (CHOOSE)

Range 1-5 1=Definitely Not

$5=$ Definitely Yes

4. Scores on SATDEV, SATCAR, CHOOSE were summated for a combined satisfaction (COMBSAT) score.

Range 0-17 with a high score indicat-

ing high satisfaction

\section{Success Measures}

5. How successful do you perceive yourself to be? (PERSUC)

Range $1-6,1=$ not at all successful $6=v e r y$ successful

6. Comparing yourself to other women

lawyers, how successful are you? (COMPW) Range $1-5,1=$ considerably less successful than most

$6=$ considerably more successthan most

7. How would other lawyers (men and

women) rate your success in compari-

son to most other lawyers? (COMPALL)

Range $1-5,1=$ considerably less successful than most

$6=$ considerably more success ful than most

8. Scores on PERSUC, COMPW, COMPALL were summarized for a combined success (COMBSUC) score.

Range 0-16 with a high score indi-

dstandard deviations appear in parentheses. 


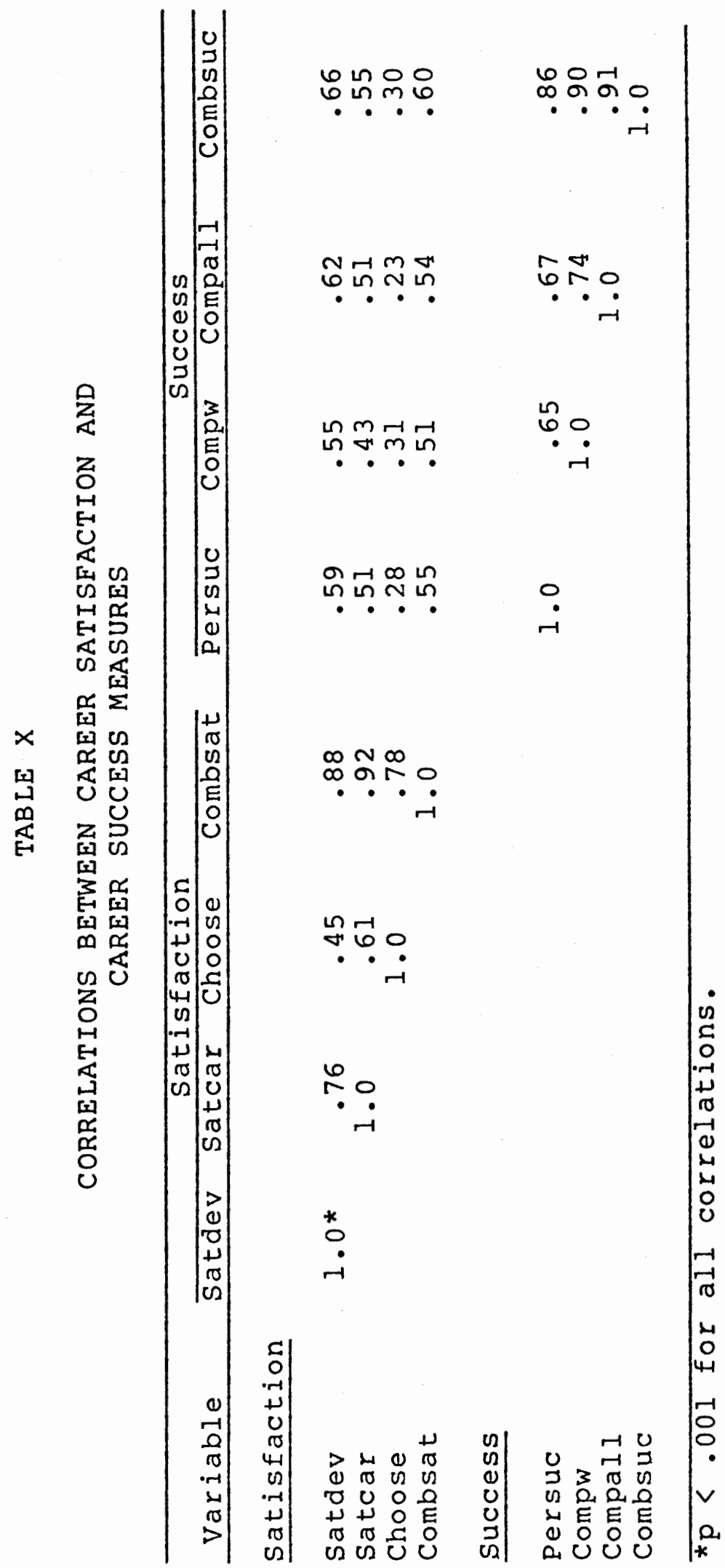


career satisfaction and success while adjusting for the effects of membership in the M/PM group. In the same manner, the effect of membership in the M/Only group was removed from the relationship between the M/PM group and outcome variables. This procedure resulted in uncovering a number of statistically significant relationships (see Tables XI and XII). Although M/ONLY appears as a stronger predictor variable than M/PM, there are no statistical differences between the two groups on the strength of their relationship to satisfaction and success. In addition, a series of two-tailed t-tests showed statistically insignificant differences between the two groups on all variables considered in this study, except one. (Not surprisingly, a woman who has been in the profession for a longer period of time was more likely to be in the mentored/pseudo-mentored group than in the mentored only group.) Based on these results, it was concluded that nothing could be gained in the ability to predict career success and satisfaction in this study by considering these two groups separately. Thus, for all remaining data analyses, the groups of M/ONLY and M/PM were treated as one group, MENTOR. The variable of MENTOR and the degree to which it was correlated with the outcome measures of satisfaction and success is presented in Tables XI and XII, respectively.

From Tables XI and XII, it can be seen that income and membership in the MENTOR group were the strongest pre- 
TABLE XI

ZERO-ORDER AND SOME FIRST-ORDER CORRELATIONS ON VARIABLES OF INTEREST WITH CAREER SATISFACTION $(\mathrm{N}=171)$

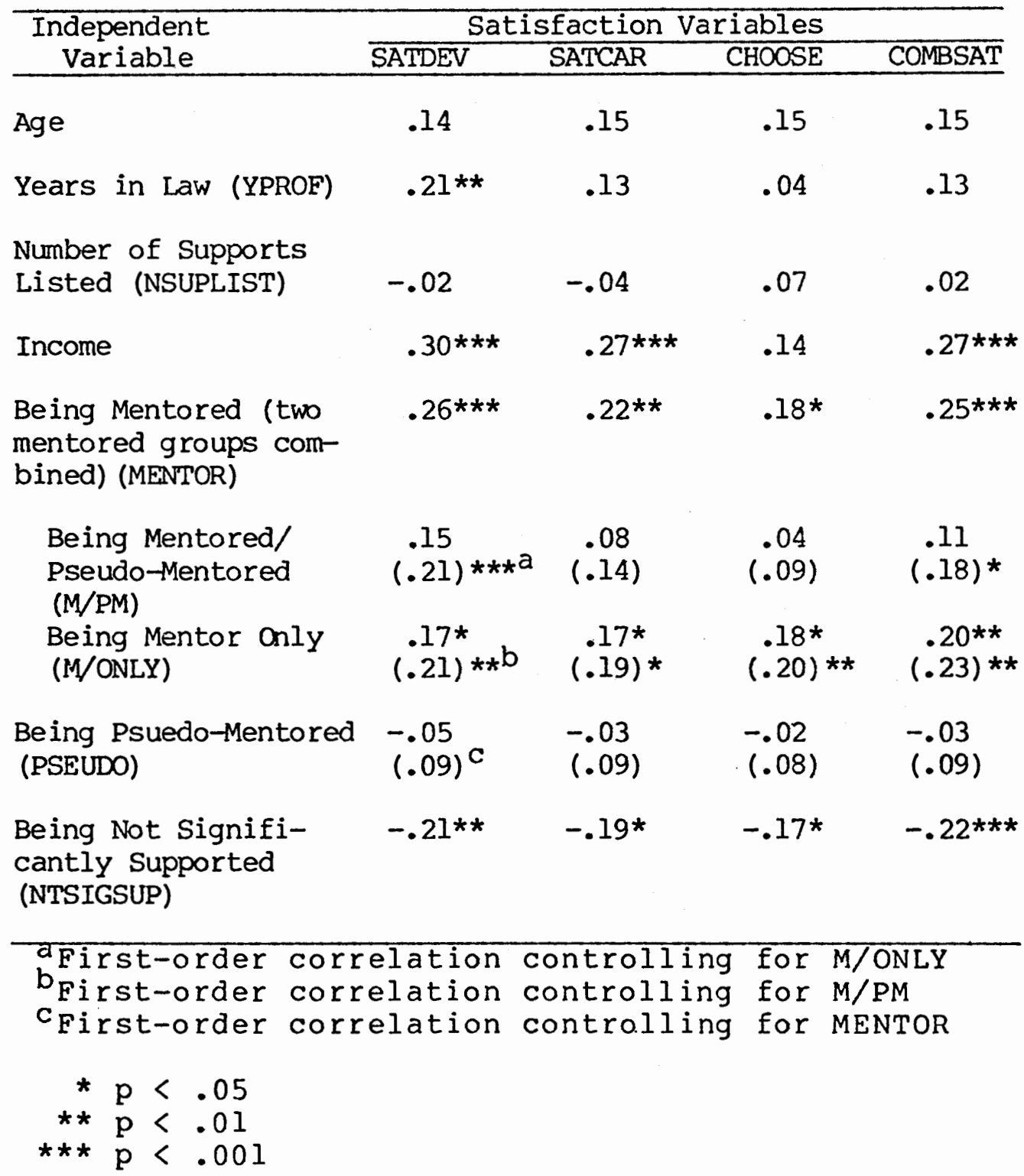


TABLE XI

ZERO-ORDER AND SOME FIRST-ORDER CORRELATIONS ON

VARIABLES OF INTEREST WITH CAREER SUCCESS MEASURES

$$
(N=171)
$$

\begin{tabular}{|c|c|c|c|c|}
\hline \multirow{2}{*}{$\begin{array}{c}\text { Independent } \\
\text { Variable }\end{array}$} & \multicolumn{4}{|c|}{ Success Variables } \\
\hline & PE $\overline{R S U C}$ & COMPW & COMPALL & COMBSUC \\
\hline Age & .14 & $.16 *$ & $.18 *$ & $.17 *$ \\
\hline Years in Law (YPROF) & $.16 *$ & $.24 * \star \star *$ & $.25 * \star \star$ & $.21 * *$ \\
\hline $\begin{array}{ll}\text { Number } & \text { Supports } \\
\text { Listed } & \text { (NSUPLIST) }\end{array}$ & .00 & .05 & .00 & .03 \\
\hline Income & $.39 * * *$ & $.48 * * *$ & $.46 * * *$ & $.48 * \star \star$ \\
\hline $\begin{array}{l}\text { Being Mentored } \\
\text { (MENTOR) }\end{array}$ & $.19 *$ & $.19 *$ & $.19 *$ & $.19 * *$ \\
\hline $\begin{array}{l}\text { Being Mentored/ } \\
\text { Pseudo-Mentored } \\
\text { (M/PM) }\end{array}$ & $\begin{array}{l}.09 \\
(.12)^{a}\end{array}$ & $(.13) *$ & $\begin{array}{l}.04 \\
(.09)\end{array}$ & $\begin{array}{l}.11 \\
(.14)\end{array}$ \\
\hline $\begin{array}{l}\text { Being Mentored Only } \\
\text { (M/ONLY) }\end{array}$ & $(.124)^{b}$ & $\begin{array}{l}.11 \\
(.15)\end{array}$ & $\begin{array}{l}.16 * \\
(.18) *\end{array}$ & $(.15)$ \\
\hline $\begin{array}{l}\text { Being Pseudo- } \\
\text { Mentored } \\
\text { (PSEUDO) }\end{array}$ & $\begin{array}{c}.01 \\
(.13)^{\mathrm{C}}\end{array}$ & $\begin{array}{l}.04 \\
(.14)\end{array}$ & $\begin{array}{r}.03 \\
(.15)\end{array}$ & $\begin{array}{l}.04 \\
(.14)\end{array}$ \\
\hline $\begin{array}{l}\text { Being Not Signi- } \\
\text { cantly Supported } \\
\text { (NTSIGSUP) }\end{array}$ & $-.21 * *$ & $-.22 * *$ & $-.22 * *$ & $-.23 * *$ \\
\hline $\begin{array}{l}{ }^{a} \text { First-order correlatic } \\
b_{\text {First-order correlatic }} \\
\text { CFirst-order correlatic } \\
* p<.05 \\
* * p<.01 \\
* * * p<.001\end{array}$ & $\begin{array}{l}\text { on contro } \\
\text { on contro: } \\
\text { on contro. }\end{array}$ & $\begin{array}{l}\text { ling for } \\
\text { ling for } \\
\text { ling for }\end{array}$ & $\begin{array}{l}\text { M/ONLY. } \\
\text { M/PM. } \\
\text { MENTOR. }\end{array}$ & \\
\hline
\end{tabular}


dictors of career satisfaction. Income, number of years in the profession, and membership in the MENTOR group, in that order, were the strongest predictors of self-perceived career success. Because this study is particularly interested in mentoring, a number of first-, second-, and third-order correlations were calculated to determine if the observed relationship between being mentored and career satisfaction and success was being affected by the variables of age, income, or number of years in the profession. The results showed essentially no change in the relationships as a result of these controls.

In addition to the interest in the variable of experiencing a true mentor relationship and its relation to career success and satisfaction, the variable of being pseudo-mentored and its relation to the same variables was of equal interest to this study. (The variable of being pseudo-mentored is described in Chapter VI.) The literature review presented in Chapter II led to the prediction that involvement in relationships such as those described in this study as pseudo-mentoring, would be positively related to career success and satisfaction. However, as can be seen in Tables XI and XII, this study found a complete absence of such relationships. In order to control for the possibility that relationships were being suppressed by some other variable or variables, a series of partial order correlations were calculated. However, upon 
controlling for the effects of age, income, and number of years in the law profession, no relationships were found. Surprisingly, even when the effects of being mentored (MENTOR variable) were removed, membership in the PSEUDO group did not significantly predict career satisfaction or success (see Tables XI and XII). However, it can also be seen in Tables XI and XII that membership in the PSEUDO group is more positively related to satisfaction and success than membership in the not significantly supported (NTSIGSUP) group. The negative relationships between being not significantly supported and each of the eight outcome variables were statistically significant, although somewhat weak.

To supplement the correlational findings, a series of two-tailed t-tests were conducted to assess the significance of differences on outcome measures between the three career support groups. The groups of MENTOR and NTSIGSUP differed significantly on all eight outcome measures. Those women in the MENTOR group consistently reported more career satisfaction and success than those in the NTSIGSUP group. It was found that the two groups of MENToR and PSEUDO differed significantly on the variables of SATDEV ( $t$ $=2.31, p<.03)$, and ComBSAT $(t=2.22, p<.03)$. Again, it was those women in the MENTOR group reporting more satisfaction. There were no significant differences between these two groups on any of the success variables. Finally, the groups of PSEUDO and NTSIGSUP did not differ 
significantly on any of the outcome variables. Tables $x x$ and XXI in Appendix G summarize these findings.

Two major findings emerged from the results presented above. First, it was found that having a true mentor (as defined in this study) was significantly related to all four satisfaction measures and all four success measures. In other words, a self-reported satisfied and successful woman in this study was also likely to be one who reported having a career-supportive person that (a) had access to resources (e.g., information, expertise); (b) performed a number of functions on her behalf (e.g., shared resources, provided advice); (c) provided for the development of her self-concept (e.g., permitted her to learn through her mistakes); and (d) became involved with her on an emotional level (e.g., was perceived by her to share feelings of mutual respect and trust). These results lend support to the view that having a mentor can be beneficial to one's career.

The second major finding of this study was that being pseudo-mentored--having a group of two or more career supports providing the kind of help and support found in a true mentoring relationship (as defined in this study)--was not related to any of the success and satisfaction measures. In other words, those women without mentors who were nevertheless in receipt of the kind of support found in a mentoring relationship, were no more likely to report 
themselves as satisfied or successful than those who were not receiving that kind of support. The literature had suggested that women with such support as pseudo-mentoring would have reported themselves not only successful and satisfied but that they would report themselves as equally if not more satisfied and successful than their mentored counterparts. Instead, those being pseudo-mentored were statistically significantly less satisfied with their career than mentored women. These results do not support the view that deriving career support from a number of individuals versus from a mentor is a desirable alternative to being mentored. The results of this study do indicate that being pseudo-mentored is better than being not supported at all; those women who were being pseudo-mentored were more likely to report themselves as successful and satisfied than those who were identified in this study as being not significantly supported. In fact, those women with the least support in this study were the least satisfied and successful. 
CHAPTER VIII

SUMMARY, CONCLUSIONS, AND RECOMMENDATIONS

The present study was conducted for the purpose of investigating three issues that were found to be problematic to the current state of knowledge on mentoring. These issues were: (a) lack of scientifically derived operational definitions in use in research on mentoring; (b) lack of agreement about how prevalent mentoring is; (c) lack of agreement about how desirable mentoring is. The information collected to address each of these issues was acquired in two phases: a literature survey, followed by a sample survey. The first issue was addressed with information collected from the literature survey; the second and third issues were addressed with data collected from the sample survey. The purpose of the literature survey was to formulate an operational definition of mentoring that could be administered to subjects in the sample survey. The operational definition that was formulated was based on an empirical profile of an "ideal" mentoring relationship. Formulation of the profile itself was a major focus of this study. It consisted of identifying 30 characteristics of the mentoring relationship from nine reports. Analysis of these characteristics resulted in the placement of each under one 
of four headings. As such, a "true mentoring relationship" was defined in this study as one which contained the following four qualities: (a) the mentor has higher status (in terms of access to resources such as information and expertise) than the mentee; (b) the mentor actively performs a number of functions for the mentee (e.g., provides technical advice); (c) there are high levels of emotional involvement on the part of both participants (e.g., there are shared feelings of respect); and (d) the development of the mentee's personal and professional selfconcept is facilitated (e.g., the mentor encourages mentee to set goals for herself).

The operational definition derived from the literature survey was presented to a group of women lawyers as a questionnaire item in the second phase of this study, i.e., the sample survey. Data collected from subjects' responses to this operationalization of mentoring were used to address the second and third issues of interest to this study: the commonness of mentoring and the efficacy of mentoring. The data collected in the sample survey were used to address the two issues separately.

First addressed was the issue of the commonness of mentoring. It was found that about one out of three (35\%) of the respondents to this study had experienced a true mentoring relationship (as defined in this study). This rate, which differed from previously reported findings on 
the prevalence of mentoring, was determined to be an outcome of the operationalization used. This study supported previous findings that variable methods of operationalizing mentoring to subjects result in variable findings on its prevalence. It is argued that scientifically derived operational definitions of mentoring such as the one used in this study give a truer measure of the commonness of mentoring than nonscientifically derived definitions and as such should be used in future research aimed at building a theory of mentoring.

since only one population (women lawyers) was surveyed, the question of the commonness of mentoring among other professional persons remains. It is recommended for future research that a scientifically based operationalization such as the one in this study be administered to several populations of professional persons and the results compared. It would be especially interesting to assess similar populations to those that had been studied previously, e.g., businesswomen, educational administrators, and other women lawyers. How will the rates compare across populations? How will the rates observed using the proposed method compare to the rates observed with less systematic measures?

It is recommended that when surveying other populations of women, the variable of age be considered. In this study, the age of the sample reflected the fact 
that it has only been within the last decade that large numbers of women have pursued law careers (Fossum, 1981). Thus, although the population was representative of the population of women lawyers on the variable of age, they were, nevertheless, relatively young when compared to the women in other studies on women and mentoring. Future research might assess the prevalence of mentoring among other groups of young women professionals, for example, young businesswomen.

In this study, neither age nor number of years in the profession predicted whether or not one had a mentor. A younger, less experienced woman was just as likely to be mentored as an older, more experienced woman. This was an important finding. It was explained by the fact that 45 percent of the women with mentors entered the field with a mentor (perhaps as a result of a mentor?) and that 93 percent of the relationships were current. It would be interesting to assess the prevalence of mentoring several years from now when it is assumed that sex-role stereotypes will have broken down. It might be speculated as to whether or not at that time women will rely on mentors to encourage them in career endeavors in traditionally male fields.

Finally, it is conceivable that the procedure used in this study for determining which women were mentored, resulted in subjects being termed mentored even though they 
might not have thought of themselves in those terms. It is known that the procedure resulted in subjects being termed not mentored when in fact they believed themselves to be. These two events were felt to be necessary outcomes; the goal of this thesis was to use a scientifically derived definition of mentoring to assess its prevalence. That is what this study accomplished. Future research might explore the consequences of such outcomes as it affects the subject. There are those who say the definition of a mentor should be left to the individual (e.g., phillips, 1977). However, it should be clear that such a procedure alone does little toward building a theory of mentoring.

With the issue of commonness of mentoring addressed, data collected from the sample survey were used to address the third issue of interest to this study. The third issue involved recent discussions in the literature regarding the efficacy of mentoring, especially. when compared to alternate and, supposedly, more accessible forms of career support. This issue was addressed in the following manner: This study first identified a group of women who did not have mentors, but who through highly supportive systems of informal support were in receipt, from more than one person, those forms of support which mentored women receive from single persons. Second, this study compared this group of "pseudo-mentored" women to the group of "mentored" 
women on the variables of self-perceived career satisfaction and success.

The literature had suggested that this study would find most of the sample to be in the pseudo-mentored group. However, it was found that 28 percent of the women were pseudo-mentored, while, as reported above, 35 percent of the women were mentored. While this is not a large difference, it does indicate a lack of support for the view that it is more common for women to enlist the help of several individuals to meet their career related needs rather than to rely on mentors to meet those needs.

The remaining 37 percent of the women were in a group termed "not significantly career supported". The nature of the support for women in this group was such that (a) they were not in receipt of at least one of the four kinds of mentoring help (above) from their systems of informal support, or (b) the help and support they were receiving from their informal supports in these four areas were not of the magnitude found in mentoring relationships. This group was included in the comparisons made between groups on the variables of career satisfaction and success. Based on those comparisons, the following conclusions were drawn: 1. The closer a supportive relationship was to true mentoring, the more likely was the woman involved to report herself as satisfied and successful in her career. In other words, the woman in the mentored 
group was more satisfied with her career and reported herself as more successful than a woman in the pseudo-mentored group. In turn, the woman in the pseudo-mentored group was more satisfied in her career and reported herself as more successful than a woman in the "not significantly supported" group.

2. Mentoring was related to career success and satisfaction and, thus, appeared as a desirable and efficient form of career support.

3. Pseudo-mentoring was not related to career success and satisfaction and, thus, did not appear as an efficient alternative to a true mentoring relationship.

4. The statistical differences in the mean ratings on two career satisfaction measures suggest that mentoring is a significantly more efficient form of career support than pseudo-mentoring.

5. The lack of statistical differences in the mean ratings on all success and satisfaction measures suggests that pseudo-mentoring is only a marginally more efficient form of career support than being "not significantly supported." 
Almquist, E. M. and Angrist, S. S. Role model influences and college women's career aspirations. Merrill-Palmer Quarterly, $17(3), 1971,263-279$.

Ard, B. N., Jr. providing clinical supervision for marriage counselors: A model for supervisor and supervisee. The Family Coordinator, 1973, 22, 91-97.

Bell, A. P. Role models in young adulthood: Their relationship to occupational behaviors. Vocational Guidance Quarterly, June, 1970, 280-285.

Bolton, E.B. Have it your way, mid-career women and their options. Vital speeches, 1978, 44, 571-573.

Bolton, E. B. A conceptual analysis of the mentor relationship in the career development of women. Adult Education, 1980, 30, 195-207.

Bova, B. M., \& Phillips, R. R. The mentor relationship: A study of mentors and proteges in business and academia. New Mexico: University of New Mexico, 1981. (ERIC Document Reproduction Service No. ED 208 233).

Burkhardt, C. M. Survival strategies for women administrators. Paper presented at Workshop on Women in Administration, Duluth, Minn., October 1979. (ERIC Document Reproduction Service No. 184 037).

Burrow, M. G. New wine in old goat-skins: Creating new management settings. Personnel Administrator, 1980, $25(4), 51 ; 53 ; 81$.

Cameron, S. M. Women in academia: Faculty sponsorship, informal social structures and career success. Ann Arbor, Mich.: Michigan University, Center for the Study of Higher Education, 1978. (ERIC Document Reproduction Service No. ED 153 557).

Cameron, S. M., \& Blackburn, R. T. Sponsorship and academic career success. Journal of Higher Education, $1981,52,369-377$.

Clawson, J. G. Superior-subordinate relationships. in managerial development. (Doctoral Dissertation, Harvard University, 1979). Dissertation Abstracts International, 1979 . 
Clawson, J. G. Mentoring in managerial careers. In C. B. Dear (Ed.), Work, Family and the Career: New Frontiers in Theory and Research. New York: Praeger, 1980

Cook, M. F. Is the mentor relationship primarily a male experience? Personnel Administrator, 1979, 24(11), 8286 .

Edson, A. S. Mentors: Do they work in PR? Public Relations Journal, $1980,36(7), 18-19$.

Epstein, C. F. Encountering the male establishment: Sexstatus limits on women's careers in the professions. American Journal of Sociology, 1970, 75, 965-982.

Erickson, K. A., \& Pitner, N. J. The mentor concept is alive and well. NASSP Bulletin, 1980, 64(440), 8-13.

Fitt, L. W., \& Newton, D. A. When the mentor is a man and the protege a woman. Harvard Business Review, 1981, $59(2), 56-57 ; 60$.

Fossum, D. Women in the legal profession: A progress report. American Bar Association Journal, 1981, 67, $578-580+$.

George, P., \& Kummerow, J. Mentoring for career women. Training, $18(2), 1981,44,45$.

Goldstein, E. The effect of same sex and cross sex role models on the subsequent academic productivity of scholars. American Psychologist, 34, 1979, 407-410.

Halatin, T. J. Why be a mentor? Supervisory Management, $1981,26(2), 36-39$.

Halcomb, R. Mentors and the successful woman. Across the Board, 1980, 17(2), 13-18.

Hennig, M., \& Jardim, A. The managerial woman. New York: Anchor Press/Double Day, 1977.

Hoffman, L. W. Early childhood experiences and women's achievement motives. The Journal of Social Issues, $1972,28(2)$.

Jennings, E. E. Routes to the executive suite. New York: McGraw-Hill Book Company, Inc., 1971. 
Johnson, M. C. Speaking from experience: Mentors-the key to development and growth. Training and Development Journal, $1980,34(7), 55-57$.

Kanter, R. M. Men and women of the corporation. New York: Basic Books, 1977.

Kellerman, B. Mentoring in political life: The case of willy Brandt. The American Political Science Review, $1978,72,422-433$.

Kirchner, E. P. Graduate education in psychology: Retrospective views of advanced degree recipients. Journal of Clinical Psychology, 1969, 25, 207-213.

Klauss, R. Formalized mentor relationships for management and executive development programs in the federal government. Public Administration Review, 1981, 41, 489496 .

LaFrance, M. Women and the mentoring process. Paper presented at the American Psychological Association Annual Convention, Los Angeles, August, 1981.

LaFrance, M. On considering aspects of the mentoring process. Behavior Today, 13, 1982, 4-5.

Levinson, D. J. The seasons of a man's life. New York: Ballantine Books, 1978.

Loring, R. K. Women and their preparation for professional and managerial careers. Columbus, Ohio: Ohio state University, Center for Research in Vocational Education, 1979. (ERIC Document Reproduction Service No. ED 181 191).

Lynch, S. M. The mentor link: Bridging education and employment. Journal of College Placement, 1980, 49, 4447.

Merkin, A. Choosing a mentor. Woman's Work, 1977, 3, 13$15,17$.

Marsicano, H. E. Role of mentors in developing careers: Do women need mentors? Paper presented at the West Virginia University Council on Women's Concerns, Morgantown, West Virginia, March 1981. (ERIC Document Reproduction Service No.. 203 132).

Missirian, A. K. The process of mentoring in the career development of female managers (Doctoral Dissertation, University of Massachusetts, 1980). Dissertation Ab- 
stracts International, 1981 ,

$4 I(8-A), \quad 3654$

(University Microfilms No. 8I-0I, 368).

Moore, K. M., \& Sangaria-Danowitz, M. A. Mobility and mentoring: Indications from a study of women administrators. Paper presented at the National Conference of the American Association for Higher Education, Washington, D. C., April 1979. (ERIC Document Reproduction Service No. ED 177 975).

Phillips, L. L. Mentors and proteges: A study of the career development of women managers and executives in business and industry (Doctoral Dissertation, University of California, Los Angeles, 1977). Dissertation Abstracts International, $1978,38(1-\mathrm{A}), 6$ 6414-6415. (University Microfilms No. 78-06, 517).

Riger, S., \& Galligan, P. Women in management: An exploration of competing paradigms. American Psychologist, $1980,35,902-910$.

Roche, G. R. Much ado about mentors. Harvard Business Review, 1979, $57(1), 14-28$.

Schmidt, J. A., \& Wolfe, J. S. The mentor partnership: Discovery of professionalism. NASPA Journal, 1980 , $17(3), \quad 45-51$.

Shapiro, E. C., Haseltine, F. P., \& Rowe, M. P. Moving up: Role models, mentors, and the "patron system". Sloan Management Review, 1978, 19(3), 51-58.

Sheeny, G. Passages: Predictable crises of adult life. New York: E. P. Dutton \& Co., 1976.

Shockley, P. S. \& Staley, C. M. Women in management training programs. Public Personnel Management, 1980 , 9, 214-224.

Speizer, J. J. Role models, mentors, and sponsors: The elusive concepts. Signs: Journal of Women in Culture and society, $198 \overline{1,6,692-712 .}$

Stein, S. L. Faculty expectations of doctoral and career mentors. Paper presented at the Annual Meeting of the Eastern Educational Research Association, Philadelphia, Penn., March 1981. (ERIC Document Reproduction Service No. 204273 ).

Stein, S. L. Sex differences in expectations of mentors. Paper presented at the Annual Meeting of the American Educational Research Association, Los Angeles, Calif., 
April 1981. (ERIC Document Reproduction Service No. 203 788).

Super, D. E. Career development: Self-concept theory. New York: College Entrance Examination Board, Research Monograph No. 4, 1963.

Super, D. E. Vocational development theory: Persons, positions and processes. Counseling Psychology, $1(1)$, 1969, 2-9.

Thompson, J. Patrons, rabbis, mentors--whatever you call them, women need them too. MBA, 1976, 10(2), 26-27; 30; $35-36$.

Vanzant, L. R. Achievement motivation, sex-role, selfacceptance, and mentor relationships of professional females. Dissertation Abstracts International, 1981, $41(10-A) \quad 4248$.

Women finally get mentors of their own. Business Week, October 23, 1978, pp. 74; 79-80.

The Woodlands Group. Management development roles: Coach, sponsor and mentor. Personnel Journal, 1980, 59, 918921 .

Wrightsman, L. S. Research methodologies for assessing mentoring. Paper presented at American Psychological Association Convention, Los Angeles, Calif., August 1981. (ERIC Document Reproduction Service No. 209 339). 
APPENDIX A

SURVEY INSTRUMENT 
Code \#

\section{CAREER SUPPORT SURVEY}

\section{Directions}

1. Please read the instructions to each question carefully. Complete all items.

2. Most of the questions about your supportive relationships are written in the present tense. When you are considering a past relationship, please answer the questions as they describe that former relationship.

3. If the response you would like to give to a question is not represented in one of the options provided, mark the most applicable option. However, you are encouraged to qualify it by writing your comments.

4. Please feel free to add any comments you vould like to share. Page 6 at the end of the questionnaire is provided for this purpose. Always indicate the question number to which you are referring when a particular question is involved.

5. When you have completed the questionnaire, place it in the return envelope provided and return it no later than

PLEASE BE ASSURED IHAI YOUR RESPONSES WILL BE KEPT ABSOLUTELY CONFIDEHIIAL. IHANK YOU FOR YOUR PARIICIPAIION.

1.

\section{Ouestions}

Iake some time right now to think back over your law career and recall those people who were and/or are a part of it. List up to five people who have played or are playing a positive role in the development of your law career. Please include on this list anyone who has been an important source of help, support, or guidance to you in your law career. These persons may include bosses, colleagues, senior colleagues, partners, parents, other relatives, co-workers, teachers, or others.

List each person by role (e.g., boss; spouse) or by roles (e.g., parent who is also a colleague; teacher who later became a boss). Include only those roles in which the person acted as an important source of help and/or support to you as you developed your career.

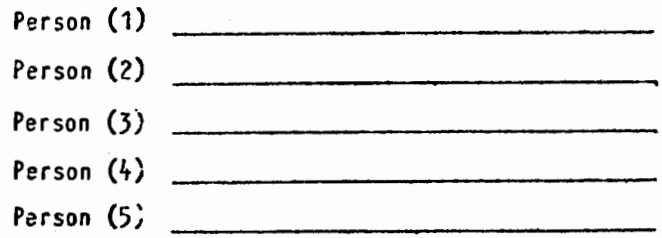

PLEASE NOIE: We vill be asking you to answer additional questions about these people. The first person you have listed here is hereafter referred to as nperson (1) $n$ in the questions that follow. The second person you have listed is hereafter refersed to as mperson (2)" and so on.

\begin{tabular}{l|l|l|l|l}
\hline Person & $\begin{array}{c}\text { Sex } \\
\text { FM }\end{array}$ & $\begin{array}{l}\text { P. } \\
\text { Person's Occupation(s) } \\
\text { at time(s) he/she was } \\
\text { a source of help/support }\end{array}$ & $\begin{array}{l}\text { 4. } \\
\text { Approximately how much older } \\
(0) \text { or Younger ( } \gamma) \text { is this } \\
\text { person than you? } \\
\text { Years o or } Y\end{array}$ & $\begin{array}{l}5 . \\
\text { Rank these persons in } \\
\text { order of importance } \\
\text { to your career with } \\
\text { "1" being "Most Important" }\end{array}$ \\
\hline$(1)$ & & & & \\
\hline$(2)$ & & & & \\
\hline$(3)$ & & & & \\
\hline
\end{tabular}

PLEASE TURN OVER- Survey is 
6A.

Using the rating scale of: $1=$ never

$$
\begin{aligned}
& 2=\text { rarely } \\
& 3=\text { sometimes } \\
& 4=\text { often } \\
& 5=\text { extremely frequently }
\end{aligned}
$$

indicate the extent to which Person (1) has provided you with the following kIisS of inELP. You should consider each as a general kind of help unless it specifically refers to your job or career.

After you have answered for Person (1), answer the question for Person (2), then, for Person (3) or for as many people as you have listed in Question 1.

KINDS OF HELP

(1) (2) $\frac{\text { Person }}{(3)}$

A. Assists you in learning the technical aspects of your job.

8. Provides advice on how to solve problems.

C. Gives feedback regarding your work.

D. Sets challenging performance standards for you to follow.

E. Serves as a model or example for you to follow.

$f$. Shares information on the customs, values, and politics of your profession or work environment.

6. Genuinely cares about you as a person.

H. Provides support and encouragement in stressful times.

I. Gives you challenging work to do that tests your abilities.

J. Helps you in planning your career.

k. Uses their influence to get you hired, promoted, or in some way to advance your career.

L. Introduces you to important others.

M. Makes sure you receive credit, recognition for your work.

N. Relates more positively to you than to most others.

0 . Acknowledges you as an accepted member of your profession.

68.

0f the kinds of help listed above, which ones would you have liked to havemore of? Place a check mark $(v)$ in the left margin beside the letter of those kinds of help.

7.

When dio this person first become a source of help/support? Answer in mos. or yrs. (e.g., 6 mos. ago; 2 yrs. 390 )
8. How satisfied are you with this relationship?

a) very dissatisfied

b) somewhat dissatisfied

c) neutral

d) somewhat satisfied

e) very satisfied

Person Letter (a,b,c,d,or e)

\begin{tabular}{l|l}
\hline Person & Answer \\
\hline$(1)$ & Per \\
\hline$(2)$ & $(1)$ \\
\hline$(4)$ & $(4)$ \\
\hline$(5)$ & $(5)$
\end{tabular}

(2)

(3)

(4)

(5)

(2)

(3)

(4)

(5)
9.

Dverall, how important has this person been to the cirection your career has : aken?

a) not at all important

b) some what unimportant

c) neutra!

g) somewhat important

E) very inoportant

iEsson Letter

(i)

(2)

(3)

$\therefore ;$

(5) 
10.

Using the rating scale of: $1=$ not at all descriptive

2 = mostly not descriptive

$3=$ somewhat descriptive

$4=$ mostly descriptive

5 = very descriptive

indicate the extent to which the following describe your relationship with Person (1). After you have answered for Person (1), answer the question for Person (2), then, for Person (3) or for as many people as you have listed in Question 1.

(1) (2) $\frac{\text { Person }}{(3)}$ (4) (5)

A. There is mutual respect and admiration in our relationship.

B. This person possesses qualities that I admire and that I have tried to make a part of myself.

c. I feel free to challenge this person's point of view.

D. This person has been like a father/mother to me at times.

E. There is a willingness to share information and exchange favors.

F. This person has had a positive influence on my self-confidence.

G. I see things in this person that remind me of myself.

H. This person makes demands of me that 1 can't meet.

I. I feel free to make mistakes without fear of repercussions.

J. I believe this person sees in me things that remind them of themselves.

K. This person encourages me to have high expectations of myself.

L. The relationship is valued in and of itself and not necessarily for the material things.

$\bar{M}$. I have experienced negative feelings toward this person (e.g., envy, resentment, inferiority, intimidation).

N. This person has access to resources (e.g., expertise, influence, information) that could advance one's career.

c. Check $(\checkmark)$ all those that apply to each person. Which persons have: a. expertise that when shared could help another's career.

b. influence/reputation among other professionals...

c. information about how to advance....................

d. ability to provide opportunities for advancement.....

e. a willingness to spend time with those needing it.....

11.

Which item below best describes this person? Someone who:

a) is presently a source of help/support

b) was helpful/supportive in the past but no longer is

c) is still helpful/supportive but not to the extent they were in the past

$\frac{\text { Person }}{(1)} \quad$ Letter
$(2)$
$(3)$
$(5)$

12.

If you answered (b) in 11, for how long a period were they helpful/supportive?

a) 0-6 mos.

b) 7 mos. -1 yr.

c) over 1 yr. -3 yrs.

d) over 3 yrs. -5 yrs.

e) over 5 yrs. - 10 yrs.

f) more than 10 yrs.

Person Letter

(2)

(3)

(4)

(5)
13.

For most of your relationship, this person has held jobs that most would consider of

a) much lesser status than yours

b) somewhat lesser status than yours

c) about equal status as yours

d) somewhat higher status than yours

person migher status than yours (1)

(2)

(3)

(4)

(5) 
THE FOLLOWING QUESTIONS DEAL WI IH YOUR CAREER IN GENERAL AND NOI WIIH INDIVIOUAL RELATIONSHIPS.

14. Overall, which best describes the amount of support/help you have received from others as your career has developed? Circle one.

$\begin{array}{ccccc}1 & 2 & 3 & 4 & 5 \\ \text { significant lack } & \text { somewhat of a } & \text { neutral } & \text { somewhat } & \text { significantly } \\ \text { of support } & \text { lack of support } & & \text { supported } & \text { supported }\end{array}$

15. iverall, how satisfied are you with the amount of support/help you have received from others? Circle One.

$\begin{array}{ccccc}1 & 2 & 3 & 4 & 5 \\ \text { very } & \text { somewhat } & \text { neutral } & \text { somewhat } & \text { very } \\ \text { dissatisfied } & \text { dissatisfied } & & \text { satisfied } & \text { satisfied }\end{array}$

16. Overall, how satisfied are you with the effectiveness of the support/help you have received from others in the course of developing your career? Circle one.

$\begin{array}{ccccc}1 & 2 & 3 & 4 & 5 \\ \text { very } & \text { somewhat } & \text { neutral } & \text { somewhat } & \text { very } \\ \text { dissatisfied } & \text { dissatisfied } & & \text { satisfied } & \text { satisfied }\end{array}$

17. In general, how satisfied are you with the progress you have made in developing your career? Circle one.

$\begin{array}{cccccc}1 & 2 & 3 & 4 & 5 & 6 \\ \text { not at all } & \text { mostly } & \text { mildly } & \text { mildly } & \text { mostly } & \text { very } \\ \text { satisfied } & \text { dissatisfied } & \text { dissatsifed } & \text { satisfied } & \text { satisfied } & \text { satisfied }\end{array}$

18. Ovarall, how satisfied are you with your career? Circle one.

$\begin{array}{cccccc}1 & 2 & 3 & 4 & 5 & 6 \\ \text { not at all } & \text { mostly } & \text { mildly } & \text { mildly } & \text { mostly } & \text { very } \\ \text { satisfied } & \text { dissatisfied } & \text { dissatisfied } & \text { satisfied } & \text { satisfied } & \text { satisfied }\end{array}$

19. If you were to do it all again, would you choose a career in law? Circle one.
Definitely Not
2
3
5

20. How successful do you perceive yourself to be? Circle one.

$\begin{array}{cccccc}1 & 2 & 3 & 4 & 5 & 6 \\ \text { not at all } & \text { mostly } & \text { mildly } & \text { mildly } & \text { mostly } & \text { very } \\ \text { successful } & \text { unsuccessful } & \text { unsuccessful } & \text { successful } & \text { successful } & \text { successful }\end{array}$

21. Comparing yourself to other komen lawyers, how successful are you? Circle one.

$\begin{array}{ccccc}1 & 2 & 3 & 4 & 5 \\ \text { considerably } & \text { somewhat } & \text { same as } & \text { somewhat } & \text { considerably } \\ \text { less successful } & \text { less successful } & \text { most } & \text { more successiul } & \text { more successful } \\ \text { than most } & \text { than most } & & \text { than nost } & \text { than most }\end{array}$

22. How would other lawyers (men and women) rate your success in comparison to most other lawyers? Circle one.

$\begin{array}{ccccc}1 & 2 & 3 & 4 & 5 \\ \text { considerably } & \text { somewhat } & \text { same as } & \text { somewhat } & \text { considerably } \\ \text { less successful } & \text { less successful } & \text { most } & \text { more successiul } & \text { more successful } \\ \text { than most } & \text { than most } & & \text { thinmost } & \text { than most }\end{array}$


PLEASE GIVE US SOME FACTS ABOUT YOURSELF:

1. Your age

2. Marital Status: Married Living as Married Never Married Separated Divorced

3. Do you have children? Yes , How Many? Wi dowed No

4. What is your religious affiliation? Catholic Protestant Jewish other Not Affiliated

5. What is your racial background? White Native American Hispanic Black Asian American Other

6. When did you:

a. Decide to become a lawyer? 19

b. Enter law school? 19

c. Graduate from law school? 19

d. Become a member of a state bar? Oregon? 19 Other state bars? Please list. 19

7. What positions have you held since leaving law school? Please list. We are asking for (a) the type of organization (e.g., solo private practice, partnership, law firm, public agency, court system, business, etc.); (b) a very brief description (1-2 words) of your position there; (c) the number of years you held this position; and (d) the approximate number of people employed thera when you started, excluding yourself.

Please start with your present position and account for all the years since your graduation from law school.

\begin{tabular}{|c|c|c|c|c|}
\hline Iype of Organization & Position & $\begin{array}{l}\text { Number of } \\
\text { yrs. in } \\
\text { position }\end{array}$ & $\begin{array}{l}\text { Number } \\
\text { employed } \\
\text { here }\end{array}$ & $\begin{array}{l}\text { How many } \\
\text { were } \\
\text { lawyers? }\end{array}$ \\
\hline & & & & \\
\hline & & & & \\
\hline & & & & \\
\hline & & & & \\
\hline & & & & \\
\hline & & & & \\
\hline
\end{tabular}

8. Please indicate your personal current income before taxes. Include only income derived directly from your practice in the legal profession.

$\$ 0-\$ 5,000$

$\$ 5,001-\$ 10,000$

$\$ 10,001-\$ 15,000$

$\$ 15,001-\$ 20,000$
$\$ 20,001-\$ 25,000$

$\$ 25,001-\$ 30,000$

$\$ 30,001-\$ 35,000$

$\$ 35,001-\$ 40,000$
$\$ 40,001-\$ 45,000$

$\$ 45,001-\$ 50,000$

$\$ 50,001-\$ 55,000$

More than $\$ 55,001$

9. Individuals who take a personal interest in helping a less experience person advance in their career have been called "mentors". Mentors "teach the ropes" of a profession, act as sponsors, and guices for the mentee, and serve as role models. Have you ever had a mentor?

$$
\text { Yes }
$$

If yes, how many? If the beginning of this survey?$$
\text { No }
$$

No

If yes, is (are) your mentor(s) someone you listed in Question 1 at Yes Person(s)

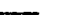

No 
This page is provided for any comments you would like to share about your relationships. If your comments have been generated by a question that appears in this survey, please indicate the question number.

Lastly, we would appreciate your comments about the survey in general should you care to add them. 


\title{
APPENDIX B
}

\author{
COVER LETTERS, \\ PHONE MESSAGE \\ AND \\ REMINDER POSTCARD
}

1. Cover Letter Sent with First Mailing

2. Follow-up Cover Letter

3. Text of Phone Message

4. Reminder Postcard 


\section{COVER LETTER SENT WITH FIRST MAILING}

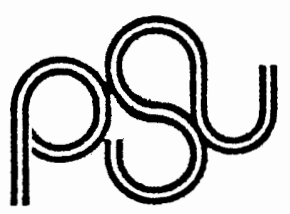

Dear

PORTLAND STATE UNIVERSITY p.0. box 75 i portland, oregon 97207 503/229-3923

department of psychology

With growing numbers of women entering traditionally male fields, like law, there is a need to understand the factors responsible for their effectiveness in these fields. A study is being conducted at Portland state university in cooperation with the Multnohmah Bar Association that may help illuminate some of these factors. One factor of particular interest is the support women receive from others as they pursue career endeavors.

Because we feel important knowledge can be gained from women who are already working in the field, you, along with the other women members of the Multnohmah Bar Association are being asked to participate in our study. You are asked to complete the enclosed survey which includes questions about the roles significant persons have played in the development and progression of your career. While many of the questions are of a personal nature, we think you'll agree that the information gained from them has the potential of adding much insight into the experiences of women who work in traditionally male fields.

So please take the time to fill out and return the enclosed questionnaire. You are assured that your individual response will be held in the STRICTEST CONFIDENCE.

It is requested that you place your survey in the mail no later than December 3, 1982. When the research is completed, all participants who desire will receive a summary of the research findings.

Thank you in advance for your time and thoughtful response.

Sincerely,

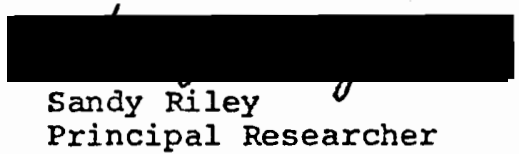

David Wrench, Ph. D. Head, Psychology Department 


\section{FOLLOW-UP COVER LETTER}

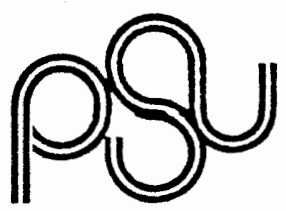

\section{PORTLAND STATE UNIVERSITY p.o. box 751 portland, oregon
97207 $503 / 229-3923$}

Dear

In mid-November, all women members of the Nultnomah Bar Association were mailed a letter requesting their participation in a study being conaucted at Portland State University. The study is designed to gather information on the role supportive others play in womens' law careers.

We were pleased with the response we received to our letter but, as you might expect, busy schedules coupled with the holidays prevented many (perhaps including yourself) from participating. Consequently, we have decided to ask once again for your help. We hope that you will complete the Career Support Survey and place it in the mail on or before January 14.

Please be assured that the information you share will be held in the strictest confidence. If you would like to receive a summary of the research findings, please indicate so on the survey form. Thank you very much for your assistance.

\section{Sincerely,}

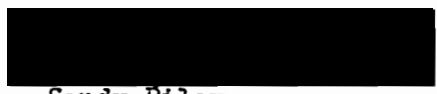

Sandy Riley

Principal Researcher

Enc.: Career Support Survey return envelope 
Hello, my name is Sandy Riley. About three weeks ago I mailed to you a letter and some materials regarding a study that is being conducted at Portland State University. The study is interested in finding out some things about women who work in traditionally male fields. Certainly your field, law, is male-dominated and therefore, we felt that your input into our study would be especially valuable in drawing conclusions about women who work in male-dominated fields.

In my letter I requested your participation in our study. participation involved filling out and returning the questionnaire that accompanied my letter. You may recall receiving that questionnaire and the reason $I$ am calling today is to request that you complete the questionnaire even though the initial deadline for doing so has passed. I've extending the deadline to December 14 for those who would like to fill out the questionnaire but so far have been too busy to do so; I wonder if you still have the questionnaire, or if not, could I send you another copy?

[Subject was allowed to respond (if she had not already interrupted the caller) and from there, no attempt was made to follow a prepared text.] 
4. REMINDER POSTCARD

Dear

In mid-December, we discussed by phone the materials you received regarding a study being conducted at Portland State University. We would like to request one final time your participation in this study. With the holidays past, perhaps you can find the time to fill out the Career support Survey. We are anxious to represent your experiences and your point of view in our results. Thank you very much. 
APPENDIX C

INFORMED CONSENT 


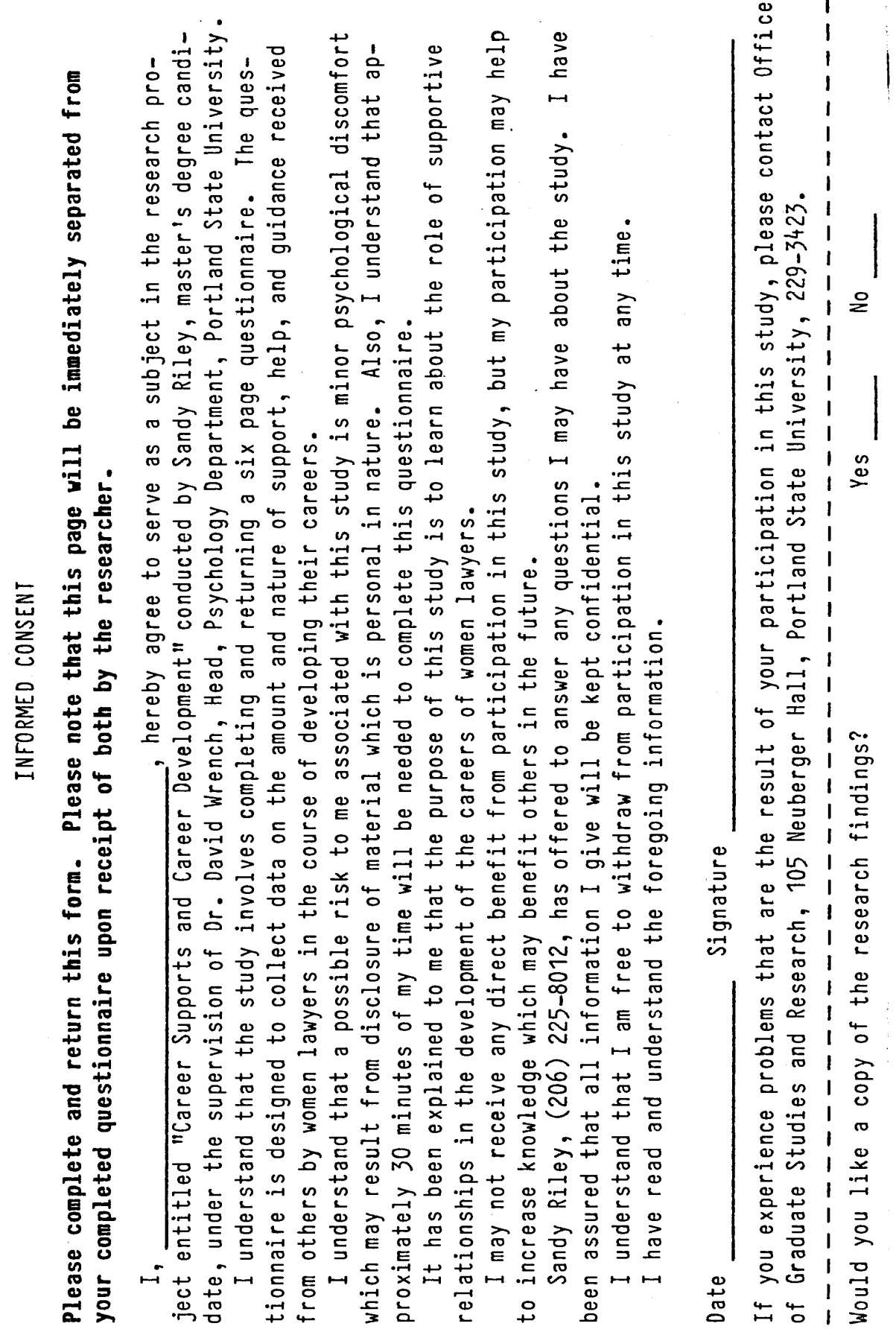


APPENDIX D

REPRESENTATIVENESS OF SAMPLE DATA 
This appendix presents the demographic characteristics for two subgroups of respondents. These subgroups are: a) those women who returned the questionnaire after the initial contact $(n=115)$, and b) those women who returned the questionnaire after a second contact $(n=56)$ or a third contact $(n=14)$. These groups are referred to as INITIAL and LATER, respectively, in the presentation below. It was intended that a comparison of these two groups would aid in determining the representativeness of the sample to the population from which it was drawn. If those women in the LATER group, who were at one time nonrespondents to this study, were not different for the FIRST group, we might assume that both groups were not different from the nonrespondents. Based on the data presented below, the sample was determined to be representative (see Chapter V).

Age. The mean age of women in the INITIAL group was $33(\mathrm{SD}=6.1$ ) years, the median age was 31.5. The mean age of women in the LATER group was $34(S D=7.0)$, the median age was 33.5. Table XIII shows the distribution of ages for these two groups.

Marital status. In the INITIAL group, 55 percent were married, 21 percent were never married, 12 percent were living as married, 12 percent were divorced and less than one percent were separated. The figures for the LATER 
group are 55 percent, 17 percent, three percent, 21 percent, and three percent, respectively.

\section{TABLE XIII}

DISTRIBUTION OF AGES FOR INITIAL AND LATER GROUPS

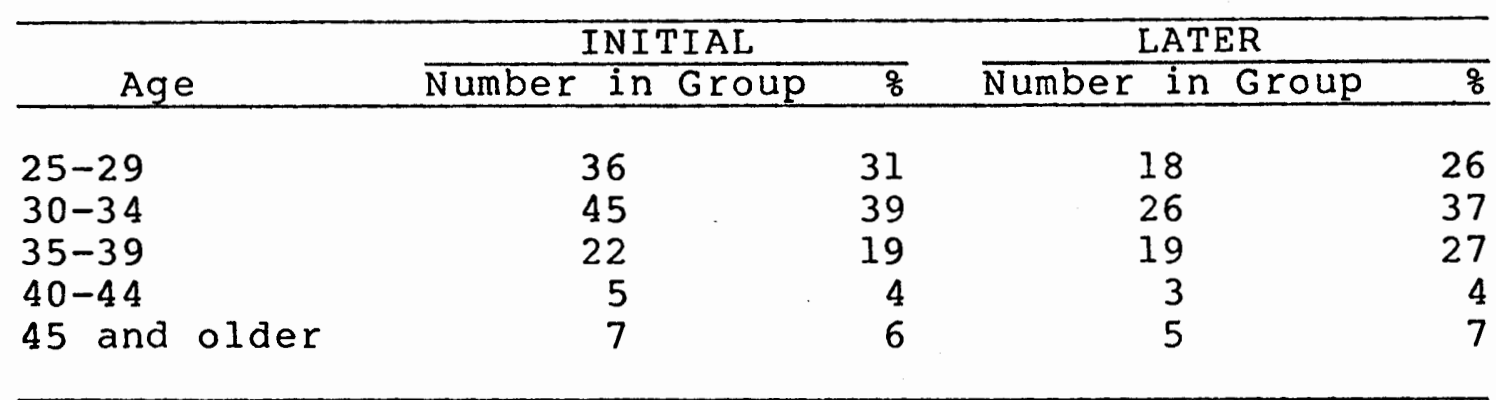

Number of Children. Thirty-four percent of the women in the INITIAL group had children, while 39 percent of the women in the LATER group had children. The mean number of children for those with children in the INITIAL group was 2.0 $(\mathrm{SD}=1.4)$. For those with children in the LATER group, the mean number of children was 2.1 (SD $=1.7)$.

Race. In both groups, over 97 percent of the women were White. other was the only additional category represented in either group.

Religion. The majority of the women in the INITIAL group were unaffiliated (39\%); in the LATER group, 41 percent were unaffiliated. protestants numbered 34 percent of the INITIAL group and 26 percent of the LATER group. Twelve percent of the INITIAL group reported themselves as Catholics while 13 percent of the LATER group did. The 
categories of Jewish represented 11 percent of the INITIAL group and 15 percent of the LATER group. The category of other represented less than three percent of the INITIAL group and five percent of the LATER group.

Years Since Law School Graduation. Table XIV gives the distribution of women in each group by year of law school graduation.

TABLE XIV

YEAR OF LAW SCHOOL GRADUATION FOR

THE GROUPS OF INITIAL AND LATER

\begin{tabular}{lcrrrr}
\hline Year of & \multicolumn{2}{c}{ INITIAL } & \multicolumn{3}{c}{ LATER } \\
\cline { 5 - 6 } Graduation & Number in Group & 8 & Number & in Group & 8 \\
\hline & 15 & 13 & 8 & 11 \\
1974 or before & 15 & 5 & 3 & 4 \\
1975 & 12 & 10 & 5 & 7 \\
1976 & 7 & 8 & 3 & 4 \\
1977 & 12 & 10 & 17 & 24 \\
1978 & 19 & 17 & 8 & 11 \\
1979 & 19 & 17 & 19 & 27 \\
1980 & 20 & 17 & 7 & 10 \\
1981 & 5 & 4 & 0 & 0 \\
1982 & & & & & \\
\hline
\end{tabular}

Number of Years in Current position. The mean number of years women in the INITIAL group have been at their curent job is 2.2 years $(S D=2.2)$, the median number of years is 1.6. The range is from less than one year to 13 years. For the LATER group, the mean number of years at their current position is $1.8(S D=1.5)$. The median number of years is 1.5 for this group. The range is from less than one year to 30 years. 
Income. Table $\mathrm{XV}$ shows the distribution of income earned by group.

TABLE XV

INCOME FOR GROUPS OF INITIAL AND LATER

\begin{tabular}{|c|c|c|c|c|c|c|}
\hline \multirow[b]{2}{*}{ Salary Range } & \multicolumn{3}{|c|}{ INITIAL } & \multicolumn{3}{|c|}{ LATER } \\
\hline & Number & in Group & $\frac{8}{8}$ & Number & in Group & 8 \\
\hline$\$ 0-\$ 10,000$ & 18 & & 16 & 1 & 0 & 15 \\
\hline$\$ 10,001-\$ 20,000$ & 26 & & 24 & 1 & 8 & 26 \\
\hline$\$ 20,000-\$ 30,000$ & 37 & & 32 & 2 & 2 & 32 \\
\hline$\$ 30,001-\$ 40,000$ & 19 & & 17 & 1 & 7 & 25 \\
\hline$\$ 40,001-\$ 50,000$ & 6 & & 5 & & 1 & 1 \\
\hline More than $\$ 50,001$ & 7 & & 6 & & 0 & 0 \\
\hline
\end{tabular}

To supplement the above data, a series of statistical tests of difference were conducted for the two groups on all the characteristics presented. These tests showed no statistically significant differences between the INITIAL and LATER groups. Table XVI summarizes the results of these tests.

\author{
TABLE XVI \\ RESULTS OF TESTS OF STATISTICAL DIFFERENCES \\ FOR GROUPS OF INITIAL AND LATER \\ ON DEMOGRAPHIC VARIABLES
}

\begin{tabular}{ccc}
\hline & T-Tests \\
$\quad$ SD & $\frac{\text { Mann-Whitney Tests }}{n \text { Mean Rank }}$ \\
\hline
\end{tabular}

Age

INITIAL

LATER

$32.8 \quad 6.1$

$34.5 \quad 7.0$

$t=1.68, d f=169, p<.10$ 


$\frac{\text { T-Tests }}{\mathrm{x}}$ SD $\frac{\text { Mann-Whitney Tests }}{\mathrm{n} \quad \text { Mean Rank }}$

Martial Status

INITIAL

LATER

$$
\mathrm{z}=.02, \mathrm{p}<.99
$$

Number of Children

\section{INITIAL}

LATER

$$
t=.69, \mathrm{df}=168, \mathrm{p}<.50
$$

Religion

INITIAL

LATER

$$
\begin{array}{ll}
.7 & 1.2 \\
.8 & 1.1
\end{array}
$$

$$
\mathrm{z}=.47, \mathrm{p}<.65
$$

\section{Race}

INITIAL

LATER

$$
\mathrm{z}=.55, \mathrm{p}<.59
$$

Law School Graduation Date
INITIAL
LATER
1977
5.0
1977
5.7
$t=.08, \mathrm{df}=163, \mathrm{p}<.94$

Number of Years at Current Job INITIAL

LATER

$\begin{array}{ll}2.2 & 2.2 \\ 1.8 & 1.5\end{array}$

$t=1.01$, df $=163, p<.32$

Income

INITIAL

LATER

$\$ 20,000-\$ 25,000$

$\$ 20,000-\$ 25,000$

$104 \quad 85.5$

66
85.6

$105 \quad 84.7$

$66 \quad 88.1$

$105 \quad 86.4$

$66 \quad 85.3$

$t=.24, d f=165, p<.82$ 
APPENDIX E

CAREER SUPPORTS BY ROLE 


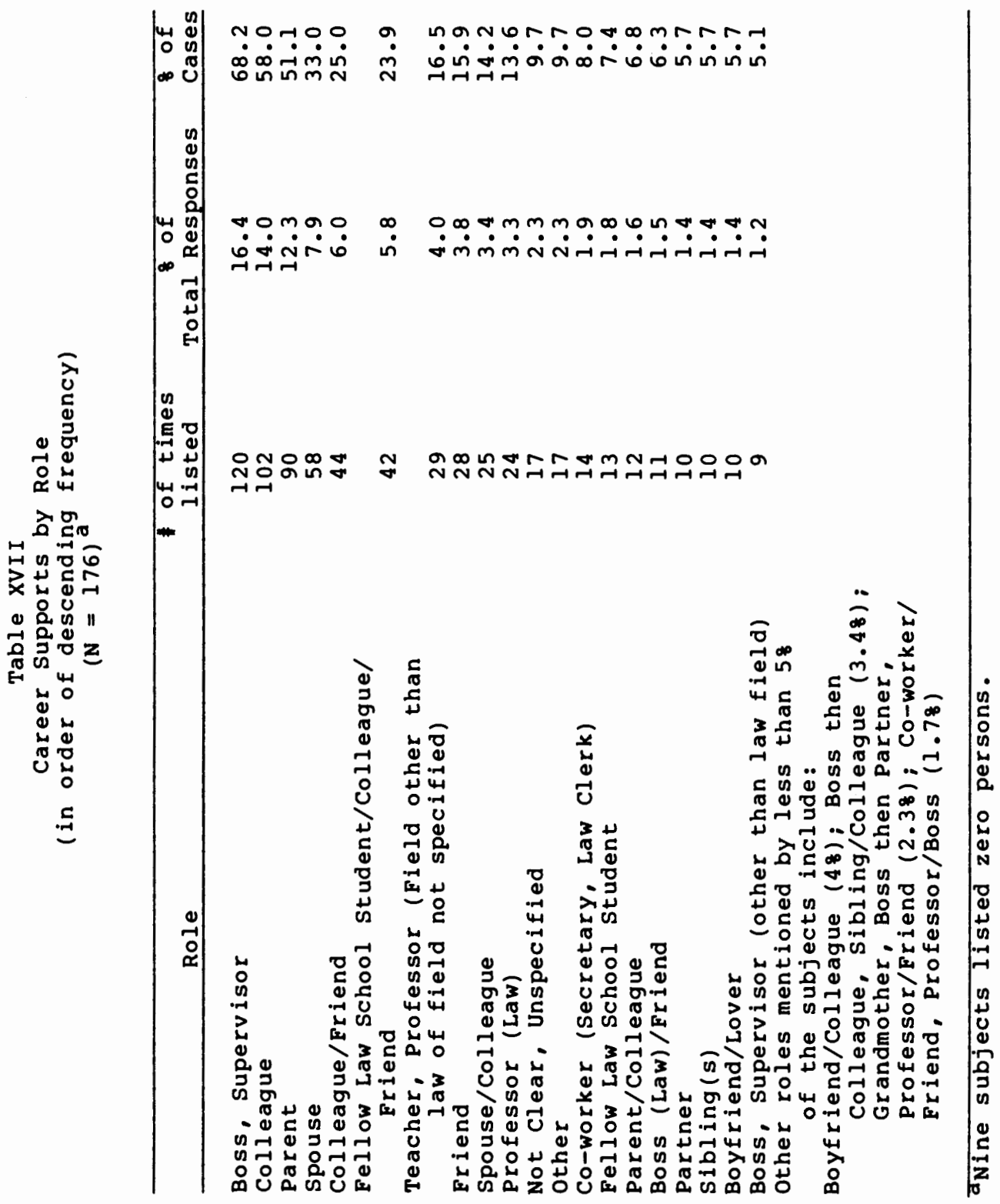




\section{APPENDIX F}

DATA ON A TYPICAL PSEUDO-MENTORED SUBJECT 


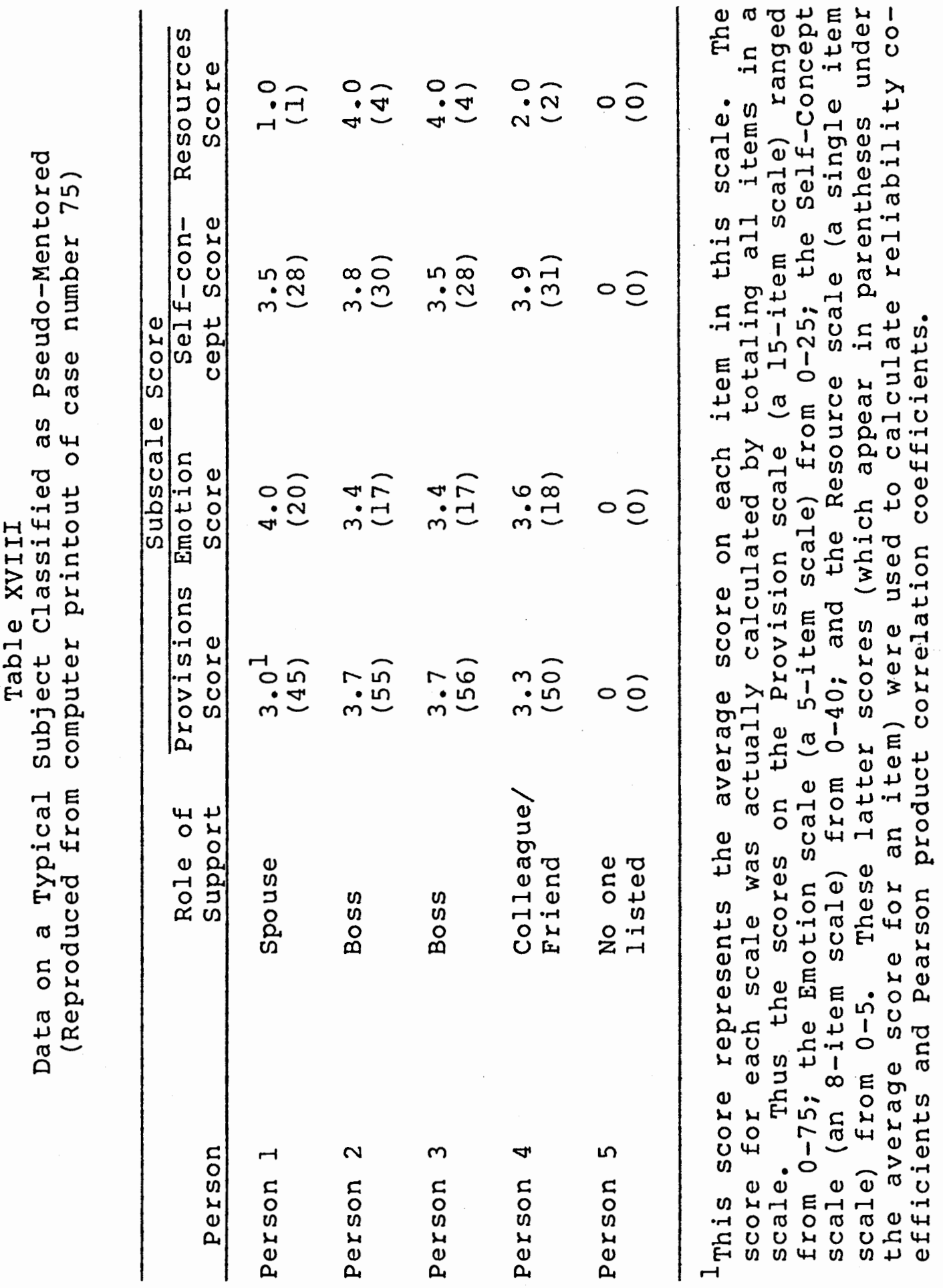


APPENDIX G

\section{TABLES}




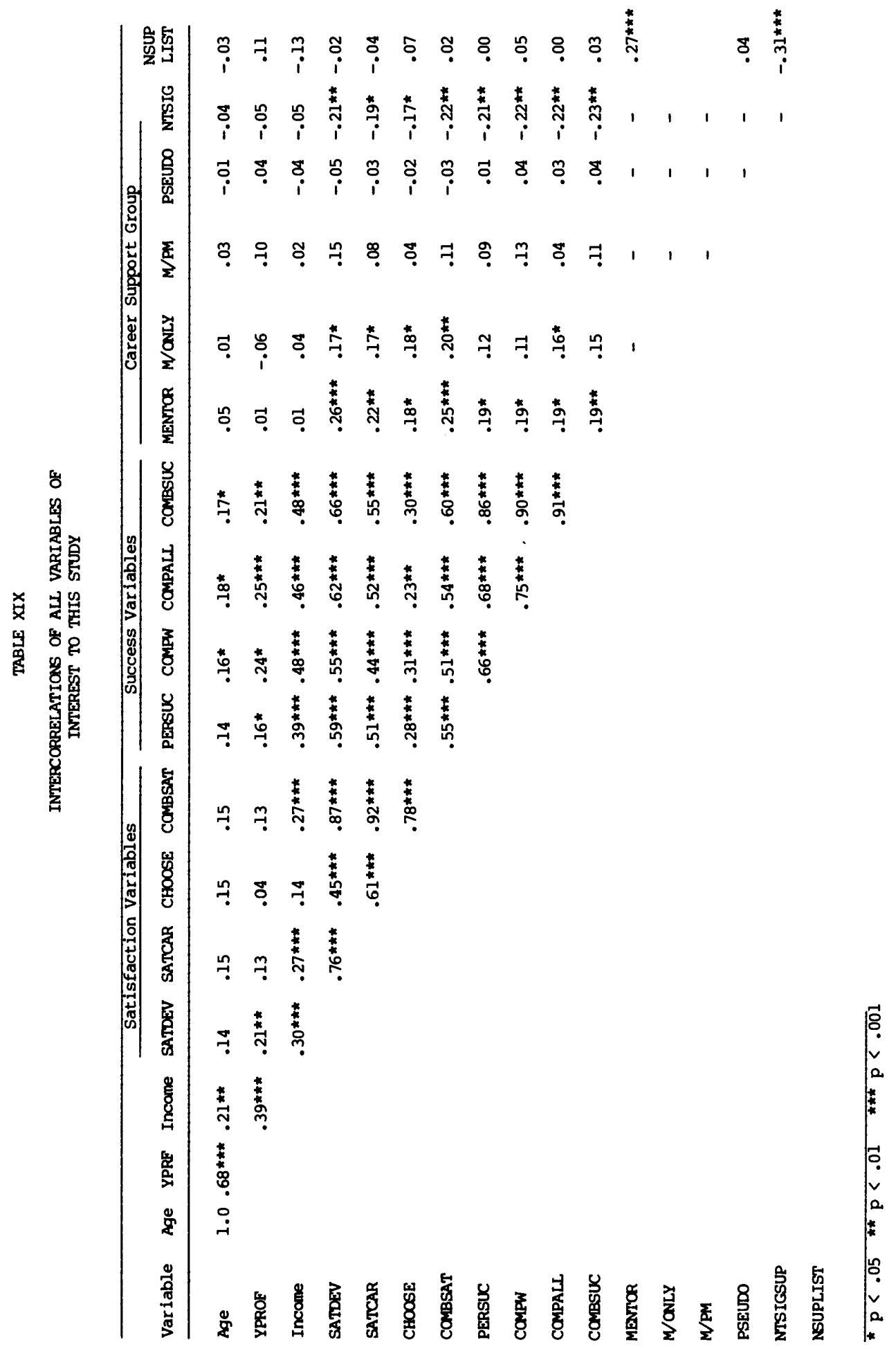


TABLE XX

SUMMARY RESULTS OF TWO-TAILED T-TESTS ON

SATISFACTION MEASURES BASED ON TYPE OF CAREER SUPPORT

Variable

SATDEV

Mentored

NtSigsup

$t=3.64, \mathrm{df}=121, \mathrm{p}<.001$

Mentored

Pseudo-Mentored

$t=2.31, \mathrm{~d} f=106, \mathrm{p}<.03$

Pseudo-Mentored

NtSigSup

$t=1.14, d f=109, \mathrm{~ns}$

SATCAR

Mentored

NtSigSup

$t=3.03, \mathrm{df}=121, \mathrm{p}<.003$

Mentored

Pseudo-Mentored

60

48

$t=1.75$, df $=106,<.08$

Pseudo-Mentored

NtSigsup

48

63

$t=1.04, \mathrm{df}=109, \mathrm{~ns}$

CHOOSE

Mentored

NtSigSup

$t=2.65, \mathrm{df}=121, \mathrm{p}<.01$

Mentored

Pseudo-Mentored

60

48

60

63

4.08

4.76

4.31

1.3

4.01

1.4

63

4.14

$1 \cdot 9$

SD

1.0

1.4

60

63

4.01
4.82
4.31

1.0

1.3

. 


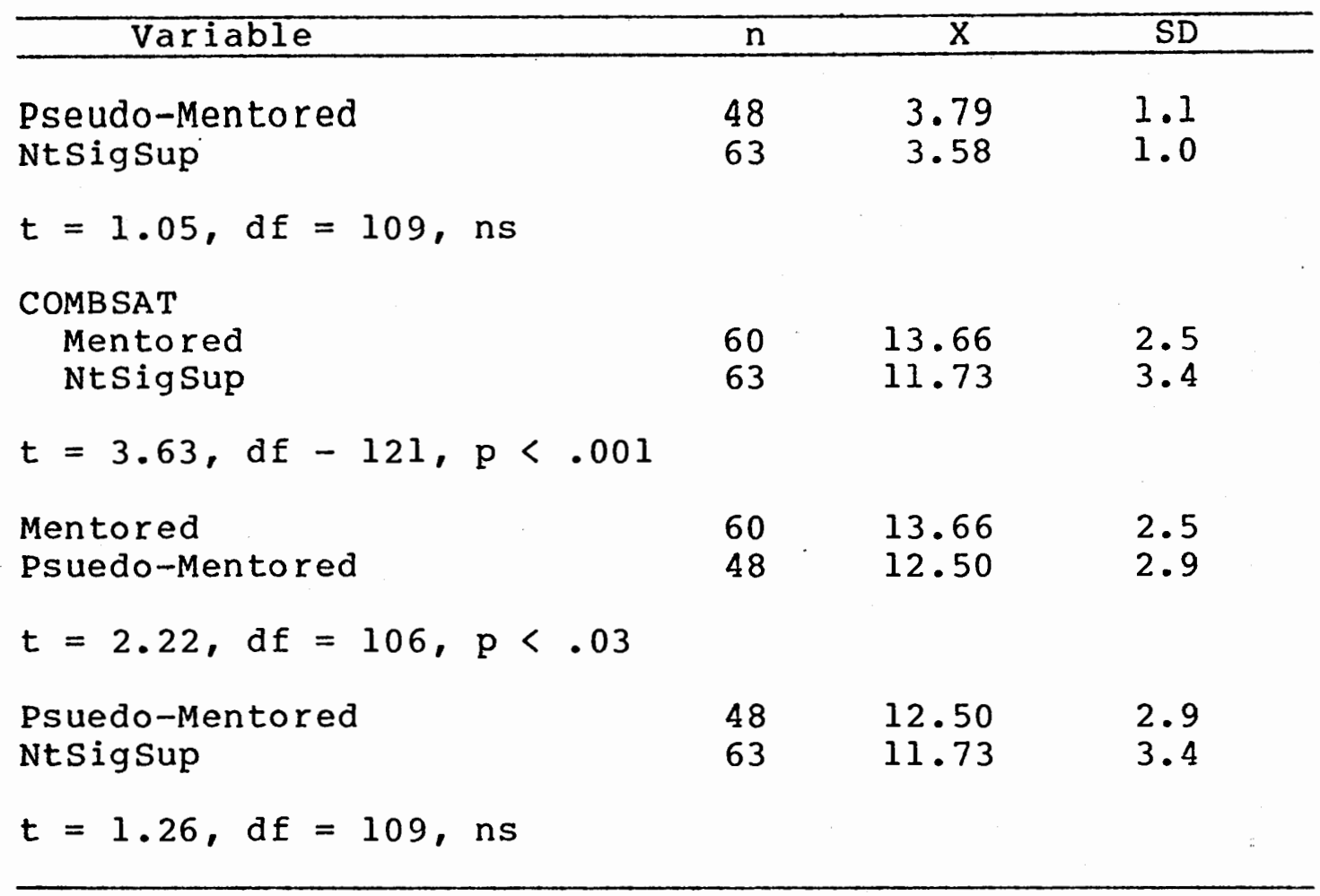


TABLE XXI

SUMMARY RESULTS OF TWO-TAILED T-TESTS ON SUCCESS MEASURES BASED ON TYPE OF CAREER SUPPORT

Variable n

PERSUC

Mentored

Ntsigsup

$t=2.76, \mathrm{~d} f=121, \mathrm{p}<.01$

Mentored

Pseudo-Mentored

$t=0.89, \mathrm{df}=106, \mathrm{~ns}$

Pseudo-Mentored

Ntsigsup

48

63

60
48

4.74

4.60

.7

.9

$t=1.50, \mathrm{df}=109, \mathrm{~ns}$

COMPW

Mentored

NtSigsup

60

63

4.05

4.60

4.34

.9

.9

$t=3.07, \mathrm{~d} f=121, \mathrm{p}<.003$

Mentored

Pseudo-Mentored

60

48

4.05

3.88

.7

.9

$t=1.09, \mathrm{df}=106, \mathrm{~ns}$

Pseudo-Mentored

Ntsigsup

48

63

3.88

3.54

.9

1.1

$t=1.71, \mathrm{df}=109, \mathrm{~ns}$

COMPALL

Mentored

Ntsigsup

60

3.83

.9

$t=2.79, \mathrm{df}=121, \mathrm{p}<.01$ 


\section{Variable}

$\mathrm{n}$

SD

Mentored

Pseudo-Mentored

$\mathrm{t}=1.01, \mathrm{df}=106 \mathrm{~ns}$

Pseudo-Mentored

NtSigSup

60

48

$\mathrm{X}$

$t=1.58, \mathrm{df}=109, \mathrm{~ns}$

COMBSUC

Mentored

NtSigsup

$\begin{array}{lll}48 & 3.65 & 1.0 \\ 63 & 3.32 & 1.1\end{array}$

$t=3.27, d f=121, p<.001$

Mentored

Pseudo-Mentored

$\mathrm{t}=1.14, \mathrm{df}=106, \mathrm{~ns}$

Pseudo-Mentored

NtSigsup

$t=1.77, d f=109$, ns

$\begin{array}{lll}60 & 12.62 & 1.9 \\ 63 & 11.20 & 2.8\end{array}$

$\begin{array}{lll}60 & 12.62 \quad 1.9\end{array}$

$48 \quad 12.13 \quad 2.6$

$\begin{array}{lll}48 & 12.13 & 2.6 \\ 63 & 11.20 & 2.8\end{array}$ 